OPEN ACCESS

Edited by:

Xiaojun Chen,

Nanjing Medical University, China

Reviewed by:

Gaoqian Feng

Burnet Institute, Australia

Celio Geraldo Freire-de-Lima,

Federal University of Rio de Janeiro,

Brazil

${ }^{*}$ Correspondence:

Xiao Yu

xiaoyu523@smu.edu.cn

${ }^{t}$ These authors have contributed equally to this work

Specialty section:

This article was submitted to

Parasite and Host

a section of the journal

Frontiers in Cellular and

Infection Microbiology

Received: 25 September 2020 Accepted: 09 November 2020

Published: 10 December 2020

Citation:

Cai C, Hu Z and Yu X (2020)

Accelerator or Brake: Immune

Regulators in Malaria.

Front. Cell. Infect. Microbiol. 10:610121.

doi: 10.3389/fcimb.2020.610121

\section{Accelerator or Brake: Immune Regulators in Malaria}

\author{
Chunmei Cai ${ }^{1,2 \dagger}$, Zhiqiang $\mathrm{Hu}^{3 \dagger}$ and Xiao $\mathrm{Yu}^{3,4 *}$ \\ ${ }_{1}^{1}$ Research Center for High Altitude Medicine, School of Medical, Qinghai University, Xining, China, ${ }^{2}$ Key Laboratory of \\ Application and Foundation for High Altitude Medicine Research in Qinghai Province, Qinghai University, Xining, China, \\ ${ }^{3}$ Department of Immunology, School of Basic Medical Sciences, Southern Medical University, Guangzhou, China, \\ ${ }^{4}$ Guangdong Provincial Key Lab of Single Cell Technology and Application, Southern Medical University, Guangzhou, China
}

Malaria is a life-threatening infectious disease, affecting over 250 million individuals worldwide each year, eradicating malaria has been one of the greatest challenges to public health for a century. Growing resistance to anti-parasitic therapies and lack of effective vaccines are major contributing factors in controlling this disease. However, the incomplete understanding of parasite interactions with host anti-malaria immunity hinders vaccine development efforts to date. Recent studies have been unveiling the complexity of immune responses and regulators against Plasmodium infection. Here, we summarize our current understanding of host immune responses against Plasmodium-derived components infection and mainly focus on the various regulatory mechanisms mediated by recent identified immune regulators orchestrating anti-malaria immunity.

Keywords: malaria, immune regulators, immune responses, type I interferon, signaling mechanisms, protective immunity

\section{INTRODUCTION}

Malaria, caused by Plasmodium, is one of the deadly infectious diseases worldwide (Battle et al., 2015; Howes et al., 2016). According to the World Health Organization report (WHO, 2019), this infectious disease affected up to 260 million individuals, and caused about half a million deaths in 2018. When female Anopheles mosquitoes inject Plasmodium sporozoites into mammalian hosts skin, the malaria infection is initiated, leading to a complex life cycle (Ross, 1896; Grassi et al., 1899). After that, the sporozoites travel through the bloodstream to the liver (Tavares et al., 2013). Once sporozoites reach the liver, they infect hepatocytes and replicate to about 30,000 merozoites, which are then released back into the peripheral blood (Mota et al., 2001). Merozoites infect red blood cells (RBCs) rapidly, and the repeated cycle, including invasions, replication and release, leads to exponential growth of parasites and disease (Amino et al., 2006; Sturm et al., 2006). The complex and multi-staged life cycle of malaria parasites evokes a slow development of immunity to protect parasites from being eliminated.

Over the past decade, the malaria disease, death, and transmission rates significantly decreased in most endemic countries. However, this stunning progress has been halted by emergence of drug resistance (WHO, 2019). Besides, the lack of an effective vaccine has been a major constraint in the 
prevention of malaria infection, which largely due to the underlying mechanism of host-parasite interactions is poorly understood (Riley and Stewart, 2013; Arama and TroyeBlomberg, 2014; Ouattara and Laurens, 2015). Malaria infection triggers a systemic immune response, and results in the increase of inflammatory cytokines production that leads to parasite elimination or disease (Stevenson and Riley, 2004; Parroche et al., 2007; Coban et al., 2010; Sharma et al., 2011; Gazzinelli et al., 2014; Kalantari et al., 2014; Wu et al., 2014; Mendonca and Barral-Netto, 2015). A fine-tuned regulation of immune responses is crucial for developing protective immunity to effectively eliminate malaria parasites and preventing overreacted damage to host. Hence, a comprehensive understanding of the molecular and regulatory mechanisms that modulate the immunity against Plasmodium is pivotal to develop effective therapeutics and vaccines.

In this Review, we briefly summarize the activation and function of immune responses to malaria invasion, and mainly focus on the immune regulators in anti-malaria immunity. We describe parasites recognition by host, and the following initiation as well as function of host immune responses. Additionally, we discuss how the known regulators manipulate above immune activation and direct our attention on our group's findings. These include that an early spike of type I interferon (IFN-I) is protective against blood stages in Plasmodium infection, which is modulated by CD40, SOCS1, FOSL1, MARCH1, as well as RTP4, regulators identified by our group and collaborators.

\footnotetext{
Abbreviations: AIM2, absent in melanoma 2; AP-1, activating protein-1; APCs, antigen presenting cells; ATF, activating transcription factor; BCR, B cell receptor; BTLA, B and T lymphocyte attenuator; BTNL2, Butyrophilin-like 2; cGAS, cyclic GMP-AMP synthase; CCL, The chemokine (C-C motif) ligand; cDCs, conventional dendritic cells; CLAG2, cytoadherence-linked asexual gene 2; CTLA-4, Cytotoxic T lymphocyte antigen-4; CXCL, Chemokine (C-X-C motif) ligand; DAMPs, danger-associated molecular patterns; DC, dendritic cell; ECM, experimental cerebral malaria; ERK, extracellular signal-regulated kinases; FOXP3, Forkhead Box P3; GC, germinal center; gDNA, genomic-DNA; GPCR, G-protein-coupled receptors; GPI, glycosylphosphatidylinositol; HVEM, Herpes virus entry mediator; IDO, Indoleamine 2,3-dioxygenase; IFN-I, type I interferon; IL, interleukin; iRBCs, infected red blood cells; IRAK, IL-1 receptor associated kinase; IRF, IFN regulatory factor; JAK, Janus kinase; JNK, c-Jun N-terminal kinases; LAG-3, Lymphocyte Activation Gene-3; MAF, musculoaponeurotic fibrosarcoma; MAPK, mitogen-activated protein kinases; MARCH1, Membraneassociated ring-CH-type finger 1; MDA-5, melanoma differentiation-associated protein 5; MAVS, mitochondrial antiviral-signaling protein; MHC, major histocompatibility complex; MSP1, merozoite surface protein 1; MyD88, myeloid differentiation factor 88; NETs, neutrophil extracellular traps; NFAT1, Nuclear factor of activated T cell 1 ; NF- $\kappa B$, nuclear factor $\kappa B$; NK cells, natural killer cells; NKT cells, NK T cells; NLRP3, NLR family pyrin domain containing 3; PAMPs, pathogen-associated molecular patterns; PD-1, programmed cell death protein 1; pDCs, plasmacytoid dendritic cells; PI3K, phosphatidylinositol 3-kinase; PRRs, pathogen recognition receptors; PyHEUL, Plasmodium yoelii HECT-like E3 ubiquitin ligase; RBCs, red blood cells; ROS, reactive oxygen species; SOCS, suppressors of cytokine signaling; STAT, Signal transducer and activator of transcription; STING, stimulator of IFN genes; TBK1, TRAF family memberassociated NF- $\kappa \mathrm{B}$ activator (TANK)-binding kinase 1; TCR, T cell receptor; Tfh cells, $\mathrm{T}$ follicular helper cells; Th cells, helper $\mathrm{T}$ cells; TIGIT, $\mathrm{T}$ cell immunoglobulin and ITIM domain; Tim-3, T-cell immunoglobulin- and mucin-domain-containing molecule 3; TLR, Toll-like receptor; TNF, Tumor necrosis factor; TNFRSF5, TNF receptor superfamily member 5; TRAF, tumor necrosis factor receptor-associated factor; Treg cells, regulatory $\mathrm{T}$ cells.
}

\section{ANTI-MALARIA IMMUNITY}

Malaria infection is initiated by the bite of mosquitoes carrying Plasmodium sporozoites. Those sporozoites target liver and infect hepatocytes when they enter the bloodstream at the first step, referred to as the liver stage. After that, merozoites released from the infected hepatocytes invade RBCs, which is called the blood stage infection. During infection, the host immune system senses the invading of Plasmodium at both liver stage and blood stage, and initiates the innate immune responses to produce cytokines and chemokines, which further activates antigen presenting cells to bridge the innate and adaptive immunity against malaria (Figure 1).

\section{Parasite Sensing}

Host detects Plasmodium-derived components [known as pathogen-associated molecular patterns (PAMPs)], including hemozoin, glycosylphosphatidylinositol (GPI) anchors, and immunostimulatory nucleic acid motifs, and host-derived damage-associated molecular patterns (DAMPs), including uric acid, microvesicles, and haem, through pathogen-recognition receptors (PRRs) (Gazzinelli and Denkers, 2006; Figueiredo et al., 2007; Schroder and Tschopp, 2010; Takeuchi and Akira, 2010; Barbalat et al., 2011; O’neill et al., 2013; Gallego-Delgado et al., 2014; Mantel and Marti, 2014). During liver stage, Plasmodium inside hepatocytes are detected by macrophages and dendritic cells (DCs) through the interaction of parasite RNA with melanoma differentiation-associated protein 5 (MDA5), resulting in production of MDA5-MAVS-IRF3/IRF7mediated IFN-I (Combes et al., 2004; Couper et al., 2010). At the blood stage, the GPI anchors from P. falciparum could stimulate pro-inflammatory responses by macrophages through recognition via TLR1/TLR2 or TLR2/TLR6 and to a much lesser extent through TLR4 (Krishnegowda et al., 2005; Walther et al., 2006; Clark et al., 2008; Riley and Stewart, 2013; Singh and Daneshvar, 2013), resulting in several downstream signaling pathways activation, including MAPK (JNK, p38, and ERK) and NF-KB signaling (Zhu et al., 2005). Hemozoincombined genomic DNA (gDNA) induces TLR9 translocation on mouse DCs and macrophages and human B lymphocytes, subsequently initiates the activation of NF- $\mathrm{KB}$ and MAPK signaling pathways, as well as the release of chemokines and cytokines (Coban et al., 2005; Coban et al., 2010). On the other hand, accumulated studies demonstrate that hemozoin-gDNA complex could also induce NLRP3/AIM2 inflammasomes (Shio et al., 2009; Kalantari et al., 2014). Besides, our results show that the activation of NLRP3/AIM2 dependent inflammasome in plasmacytoid DCs (pDCs), conventional DCs (cDCs), and macrophages during P. yoelii YM infection (Yu et al., 2018). We also demonstrate that the P. yoelii YM gDNA initiates low level of IFN-I induction via cGAS-STING-TBK1-IRF3 (Yu et al., 2016). Our and other studies indicate that during both the liver and blood stage, parasites RNA activates MDA5-MAVSmediated IFN-I production with murine parasites (such as $P$. yoelii and P. berghei) or human Plasmoidums (such as P. falciparum) treatment in DCs and macrophages (Baccarella et al., 2013; Liehl et al., 2014; Wu et al., 2014; Yu et al., 2016). 


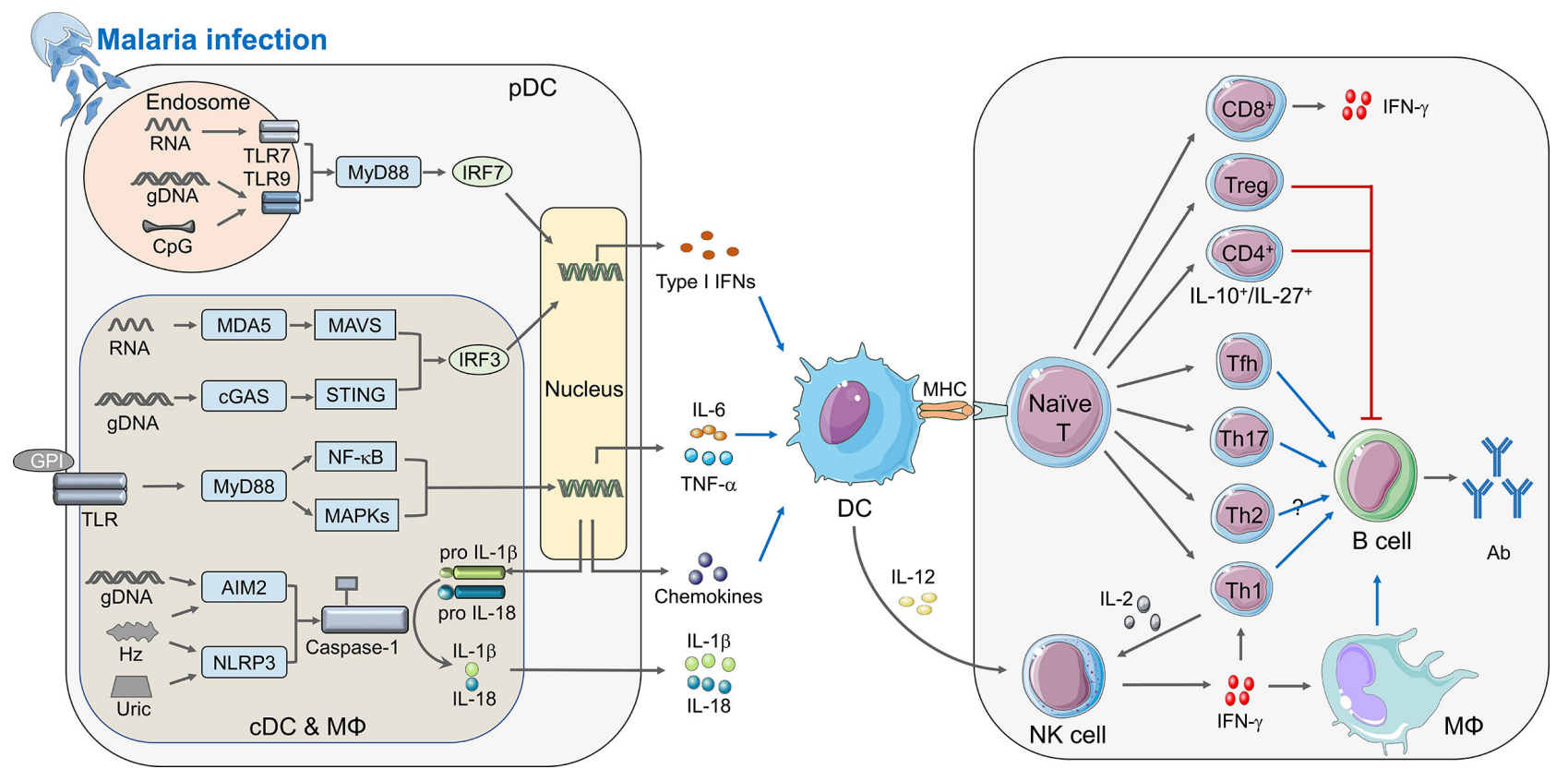

FIGURE 1 | Immune responses elicited by Plasmodium infection. During malaria infection, different PAMPs secreted from merozoites can be sensed by PRRs and activate the innate immunity (left panel). cDCs, macrophages, and pDCs are the crucial innate immune cells to defend malaria infection. Within the cytosol of these cells, pathogenic RNA interacts with MDA5 and recruits the adaptor protein MAVS, and Plasmodium gDNA can be detected by cGAS or other DNA sensors to activate adaptor protein STING. Both MAVS and STING could recruit serine/threonine-protein kinase TBK1 to phosphorylate IRF3 which translocate to nucleus and induce the expression of IFN-I. Furthermore, parasitic nucleic acid gDNA can also be sensed by inflammasome sensors AIM2, whereas haemozoin and uric acid activates NLRP3, leading to activation of inflammasomes and Caspase-1, which cleave pro-IL-1 $\beta$ and pro-IL-18 to form mature IL-1 $\beta$ and IL-18. Besides, parasite glycosylphosphatidylinositol (GPI) anchors to TLRs, including TLR2-TLR6 or TLR1-TLR2 heterodimers and TLR4 homodimers. TLRs signal transduces through MyD88, which finally causes the activation of NF- $\mathrm{BB}$ and MAPKs, and induces the secretion of pro-inflammatory cytokines, such as TNF- $\alpha$ and IL-6, as well as chemokines. Specifically, both CpG and hemozoin-combined gDNA can induce TLR9 translocation, and TLR7 can sense parasite RNA in the endosome of pDCs during the early infection stage, TLR9 as well as TLR7 recruit adaptor protein MyD88 and kinases TRAFs to phosphorylate IRF7 and induce the early robust production of IFN-I. After the innate immune responses, DC acts as a vital APC receiving stimulation via cytokines described upon, is activated and presents the antigens to naïve T cell through combination of MHC and TCR, which builds a bridge between innate and adaptive immunity. During adaptive immunity (right panel), naïve T cells differentiate into different subtypes with unique functions in anti-malaria immunity. Tfh, Th1, and Th17 could facilitate function of B cells, while Treg and $\mathrm{IL}-10^{+} / \mathrm{LL}-27^{+} \mathrm{CD} 4^{+} \mathrm{T}$ cell can suppress B cell function; CD8 ${ }^{+} \mathrm{T}$ cells mainly express IFN- $\gamma$, and leaving function of Th2 is still uncertain. Activated DCs can also secrete IL-12 to promote the expression of IFN- $\gamma$ from NK cell, which can enhance function of Th1 and macrophage thus help B cells to secrete antibody. Besides, IL-2 produced by Th1 can help NK cell to kill parasites. The diagram depicts a simplified version of indicated signaling pathway and immune cells involved in antimalaria immunity. The abbreviations are defined in footnote.

In addition, our and other studies denote that the RNA of blood stage parasites induces IFN-I responses through TLR7 signaling pathway (Torgler et al., 2008; Baccarella et al., 2013; Soulat and Bogdan, 2017; Ding et al., 2018). Uric acid, released in large amounts by dying cells, is a byproduct of purine metabolism (Kordes et al., 2011). The pathogenic role of uric acid arises from NLRP3 activation and the inflammatory responses during malaria (Artavanis-Tsakonas and Riley, 2002; Baratin et al., 2007; Griffith et al., 2009; Chen et al., 2014). Host cell-derived microvesicles and haem also trigger inflammatory responses and pathogenesis of malaria (Couper et al., 2010; Ferreira et al., 2011; Mantel and Marti, 2014).

\section{Innate Immunity}

The innate immune responses provide a powerful front line defense against invasive malaria by inhibiting parasite growth and initiating the development of adaptive immunity (Deroost et al., 2016; Thaiss et al., 2016). During the liver stage of malaria infection, recent studies have demonstrated that sporozoites can be phagocytized by neutrophils, which are usually the first circulating cells to respond to an invading Plasmodium sporozoites through a mosquito bite (Segal, 2005; Peters et al., 2008; Hopp and Sinnis, 2015). At the blood stage infection, neutrophils clear merozoites via phagocytosis by producing reactive oxygen species (ROS) and other antimicrobial products or by formatting neutrophil extracellular traps (NETs) (Kumaratilake and Ferrante, 2000; Baker et al., 2008; Dale et al., 2008; Dupre-Crochet et al., 2013; Kapelski et al., 2014; Manfredi et al., 2018). The monocytes/macrophages are also important in eliminating parasite to protect host from disease (Chua et al., 2013). Kupffer cells play a pivotal role in preventing the severity of malaria and the release of the parasite into the bloodstream (Tweedell et al., 2015; Tweedell et al., 2018). During the blood stage of malaria, the circulating monocytes are pivotal to control parasitemia by phagocytose merozoite and asexual infected RBCs (iRBCs), as well as by increased inflammatory cytokines (IFN- $\alpha$, IFN- $\gamma$, TNF- $\alpha$, and IL-6) and chemokines (CCL2, CCL3, CCL4, and 
CXCL10) (Huang et al., 2014; Colborn et al., 2015; Bansal et al., 2016; Hommel et al., 2018). Besides, the splenic macrophages play a key role in reducing blood stage parasitemia by phagocytosing iRBCs and producing reactive oxygen intermediates (Sponaas et al., 2009).

Type I IFNs play important roles in controlling malaria infection. An early spike of IFN-I is protective against some $P$. yoelii or P. berghei models (Liehl et al., 2014; Wu et al., 2014; Yu et al., 2016). Although the mechanisms remain largely unknown, studies have also shown that chronically high levels of IFN-I inhibit $\mathrm{T}$ cell activation, IFN- $\boldsymbol{\gamma}$ production and humoral immunity; as well as promote DCs death (Haque et al., 2011; Haque et al., 2014; Tamura et al., 2015; Montes De Oca et al., 2016; Zander et al., 2016). During liver stage of malaria infection, IFN-I could be induced by sporozoites in hepatocytes through cytosolic sensing of RNA (Liehl et al., 2014; Miller et al., 2014). At the blood stage, type I IFNs are the earliest cytokines produced by $\mathrm{pDCs}$ via TLR7-MyD88-IRF7 signaling pathway. By using lethal model of $P$. yoelii YM infection, our studies have showed that production of early type I IFNs are mediated by TLR7-MyD88-IRF7 signaling pathway and cytosolic sensing mechanisms, which include AIM2/NLRP3-Caspase1-IL-1 $\beta$ TRAF3-TBK1-IRF3, cGAS-STING, and MDA5-MAVS associated TBK1-IRF3 signaling pathways (Yu et al., 2016; Yu et al., 2018). We further identified SOCS1, expressed in response to cytosolic sensing mechanisms, as a vital regulator to inhibit TLR7-MyD88-dependent IFN-I signaling (Yu et al., 2018). Type I IFNs contribute to the killing of parasite-infected hepatocytes by priming efficient cytokines and chemokines as well as activating $\gamma \delta \mathrm{T}, \mathrm{T}$, natural killer $(\mathrm{NK})$, and NKT cells to induce IFN- $\gamma$ and other inflammatory cytokines production (Mcnab et al., 2015). The IFN- $\gamma$ is an important effector that contributes to activating immune cells and indirectly eliminating parasiteinfected cells (Liehl et al., 2014; Miller et al., 2014; Stegmann et al., 2015).

\section{Bridging Innate and Adaptive Immunity}

DCs exist in all clinically relevant sites related to the life stage of the malaria parasites and play a vital role in bridging the innate and adaptive immune system (Wykes and Good, 2008). Upon taking up foreign antigens or infecting by malaria parasites, DCs undergo a process of maturation and efficiently present antigen to pathogen-specific T cells via major histocompatibility complex (MHC) surface molecules (Stevenson et al., 1995; Stevenson and Riley, 2004; Orsini et al., 2012). Besides, the DCs secrete several cytokines and chemokines to recruit other immune cells and regulate $\mathrm{T}$ and $\mathrm{B}$ cells responses, ultimately resulting in clearance of malaria parasites (Wykes et al., 2007; Gowda et al., 2012; Orsini et al., 2012; Wu et al., 2014). An important mechanism for mice to resist Plasmodium infection is that the production of IL12 in DCs, which then initiates the NK cells release IFN- $\gamma$ to polarize $\mathrm{CD}^{+} \mathrm{T}$ helper cell 1 (Th1) (Stevenson et al., 1995; Stevenson and Riley, 2004; Wykes et al., 2007; Gowda et al., 2012). The $\mathrm{CD} 4^{+}$Th1 cells evoke effector responses and maintain the memory $\mathrm{T}$ cell pool to protect host from Plasmodium infection for a long-term (Da Silva et al., 2013). The DCs can be roughly divided into $\mathrm{pDCs}$ and $\mathrm{cDCs}$ population according to the expression of CD11c and CD123 (Macri et al., 2018). pDCs are the main sources of IFN- $\alpha$, while $\mathrm{cDCs}$ are specifically used to prime and present antigens to T cells (Orsini et al., 2012; Macri et al., 2018). Besides, our studies suggest that pDCs, cDCs, and macrophages are required for generating IFN-I responses against $P$. yoelii $\mathrm{YM}$ infection in a stage-specific manner ( $\mathrm{Yu}$ et al., 2016).

\section{Adaptive Immunity}

Upon DCs presenting processed antigens to naïve T cells, adaptive immunity is activated. Parasite-specific cytotoxic $\mathrm{CD}^{+}{ }^{+}$cells are essential for the liver-stage protection upon recognition of Plasmodium antigens present on MHC class I expressed by DCs and infected hepatocytes (Sedegah et al., 1992; Doolan et al., 1997; Doolan et al., 2003). Yet, at the blood stage of malaria infection, iRBCs have lost the ability to express MHC-I leading to little contribution of $\mathrm{CD}^{+} \mathrm{T}$ cell-mediated cytotoxicity to control malaria infection (Kumar and Miller, 1990; Vinetz et al., 1990; Miyakoda et al., 2012). Besides, the function of $\mathrm{CD}^{+} \mathrm{T}$ cells in controlling cerebral Plasmodium in human is still controversial (Hunt et al., 2010; White et al., 2010). CD ${ }^{+}$T cells can be activated by specific polarized cytokines to differentiate into functionally diverse subsets. $\mathrm{CD} 4^{+}$Th cells are able to target MHC class II molecules, and play a crucial role in orchestrating innate and adaptive immunity during malaria infection (Roestenberg et al., 2009; Seder et al., 2013; Ishizuka et al., 2016; Mordmuller et al., 2017). IFN- $\gamma$ and IL-2 are the $\mathrm{CD}^{+}{ }^{+}$Th1-associated cytokines (Shear et al., 1989; Su and Stevenson, 2000; Horowitz et al., 2010). During blood stage Plasmodium infection, IFN- $\gamma$ is essential to activate macrophages and tune class-switch recombination in parasite-specific B cells to evoke antibody response, while IL-2 is critical for activating NK cells (Su and Stevenson, 2000; Jaramillo et al., 2003; Horowitz et al., 2010). The contribution of CD4 ${ }^{+}$Th2 cells remains unknown in anti-malaria immunity (Perez-Mazliah and Langhorne, 2014; Coomes et al., 2015; Walker and Mckenzie, 2018). The $\mathrm{T}$ follicular helper (Tfh) cells broadly express the chemokine receptor CXCR5, the transcriptional repressor BCL6 , and the inhibitory receptor programmed cell death protein 1 (PD-1) (Vinuesa and Cyster, 2011). Multiple reports have suggested that Tfh cells, locating at germinal center (GC), can promote protective antibody responses against malaria via providing selection, survival and maturation signal to differentiate GC B cells (Obeng-Adjei et al., 2015; Ryg-Cornejo et al., 2016; Figueiredo et al., 2017; Perez-Mazliah et al., 2017). However, in human malaria, unlike GC Tfh cells, the subsets of circulating Tfh (cTfh) cells play diverse role in anti-malaria immunity. Th1-cTfh cells exhibit a negative role in eliminating parasite, while Th2-cTfh positively correlates with functional antibodies in anti-malaria immune responses (Crotty, 2019; Chan et al., 2020). The Th17 subset is expanded and meaningfully protects host from malaria infection through supporting GC reactions as well as $\mathrm{CD}^{+} \mathrm{T}$ cell responses (Wei et al., 2007; Moretto et al., 2017). Another subsets CD4 ${ }^{+}$-derived T cells, including those expressing IL-27 and IL-10, appear to inhibit parasite control and protective immunity during Plasmodium 
infection (Couper et al., 2008; Freitas Do Rosario et al., 2012; Gwyer Findlay et al., 2014; Kimura et al., 2016). Treg cells are a subset of $\mathrm{CD}^{+} \mathrm{T}$ cells that specifically express the transcription factor FOXP3. In the clinical studies, the Treg cell populations expand after malaria infection. In addition, Treg cell frequency was positively correlated with parasite load (Jangpatarapongsa et al., 2008; Torcia et al., 2008; Hansen and Schofield, 2010). Several experimental studies have shown that during blood-stage malaria, Treg cells block effective interactions between Tfh and B cells in GC responses during blood-stage infection (Abel et al., 2012; Kurup et al., 2017).

During a primary infection, antibody-independent immune mechanism can usually limit the severity of malaria infection. However, the B cells and antibodies are essential for complete parasite clearance and providing protection against reinfection, which are coordinated by $\mathrm{CD} 4^{+} \mathrm{Th} 1$ cells via indirectly targeting iRBCs, lacking expression of MHC molecules (Mendis and Targett, 1979; Osier et al., 2008; Fowkes et al., 2010; PerezMazliah et al., 2015; Stone et al., 2018). Hence, studying B-cell responses to Plasmodium at the monoclonal level has great potential for the development of effective vaccines and therapies (Imkeller et al., 2018; Murugan et al., 2018; Alanine et al., 2019; Mcleod et al., 2019). The antibody-dependent immune responses target circulating parasites and infected host cells expressing parasite antigens on their surfaces (Doolan et al., 2009). Several studies have indicated that the protective antibody titers could not be efficiently induced to against malaria both at liver- and blood-stage, which arise from no time for maturation of long-lived antibody-secreting plasmablasts and highly variable antigen-mediated immune escape of merozoites, respectively (Hoffman et al., 1987; Wahlgren et al., 2017; Aliprandini et al., 2018). Besides, multiple studies hypothesized that $\mathrm{B}$ cell responses might be suboptimal or dysfunctional after malaria parasites infection, resulting in defective long-lasting humoral memory (Marsh et al., 1989; Gupta et al., 1999; Silveira et al., 2018). To support above assumption, a series of field studies have indicated that Plasmodium-specific antibody responses retain a much shorter lifespan than their homologous memory B cell responses, especially in children (Crompton et al., 2010; Weiss et al., 2010; Ndungu et al., 2012; Ndungu et al., 2013). Recent advance has suggested that during the blood stage, the shortlived plasmablasts expand to constrain GC-dependent humoral immunity both in human and mice (Vijay et al., 2020). Interestingly, several reports have shown that antibodies could activate the complement system to against parasites (Ratelade and Verkman, 2014; Kurtovic et al., 2020). Antibody-mediated complement activation can protect and enhance antibody efficacy by exploiting Fc-mediated neutralization and lysis of target cells. Notably, complement-mediated lysis is strongly observed in human, guinea pig, and rat serum, except for mouse. Furthermore, The AMB, T-bet-expressing B cells, expands in blood stage during Plasmodium infection (Weiss et al., 2009). The function of T-bet ${ }^{+}$AMB (atypical memory B cells) on host protection from malaria infection is still undetermined (Barnett et al., 2016; Rivera-Correa et al., 2017).

\section{REGULATORS IN ANTI-MALARIA IMMUNE RESPONSES}

Anti-malaria immune responses are tightly modulated to maintain host defense and immune balance. These include positive regulators to accelerate the immune responses and negative regulators to attenuate the immunity. Over the past decades, many immune regulators have been identified (Figure 2), which could lead to beneficial or detrimental outcomes for the host. Understanding how anti-malaria immune responses are regulated by these regulators will obviously facilitate the development of new effective vaccines and therapies. Next, we summarize the current knowledge of the positive and negative regulators involved in anti-malaria immune responses and discuss the mechanism by which these regulators orchestrate host immunity against malaria.

\section{Positive Regulators CD40}

CD40 (or TNFRSF5), a member of TNF receptor superfamily, is broadly expressed on the surfaces of many cell types, including monocytes, DCs, B cells, endothelial cells, and epithelial cells (Van Kooten and Banchereau, 2000). The signal transduction mediated by CD40-CD40L interaction could activate NF- $\kappa B$, STAT3, MAPK, and other kinases (Van Kooten and Banchereau, 2000; Elgueta et al., 2009). Accumulated studies have indicated that CD40 is responsible for promoting cellular and humoral adaptive immunity and inflammatory responses (Van Kooten and Banchereau, 2000; Benveniste et al., 2004; Elgueta et al., 2009; Carlring et al., 2011). Besides, interaction of CD40 and CD40L between the DCs and $\mathrm{CD}^{+} \mathrm{T}$ cells triggers DCs to activate cytotoxic $\mathrm{CD}^{+}$cells (Bennett et al., 1998; Ridge et al., 1998; Schoenberger et al., 1998). Recent advances suggested that CD40-CD40L ligation could initiate the activation TRAF2/3 mediated NF- $\mathrm{KB}$ pathways and production of IRF1 to eventually induce IFN- $\beta$ expression (Stirnweiss et al., 2010; Moschonas et al., 2012). CD40 was reported to help eliminating the malaria parasites to reduce the severity of disease (Inoue et al., 2012; Murray et al., 2015; Gramaglia et al., 2017; Parmar et al., 2018). Yao et al. found that CD40 could compete with STING to bind TRAF2/3 and/or TRAF6 to reduce STING ubiquitination, leading to dampen STING degradation and increase STING protein level (Yao et al., 2016). The increase of CD40 expression by $P$. yoelii N67 infection could enhance the protein level of STING, which in turn promotes the IFN-I production during early stage of infection and results in better host survival (Yao et al., 2016). It is also indicated that iRBCs, parasite DNA/RNA, and various TLR ligands, could induce CD40 expression. After malaria infection, a signaling axis of TLR recognition and signaling is established, leading to increase CD40 and STING levels, enhance IFN-I production, and prolong host survival (Yao et al., 2016).

\section{CD28}

CD28 constitutively expresses on T cells surface (Gross et al., 1992). The CD80/86-CD28 interaction between APCs and T cells is an important costimulatory signal for $\mathrm{T}$ cell 


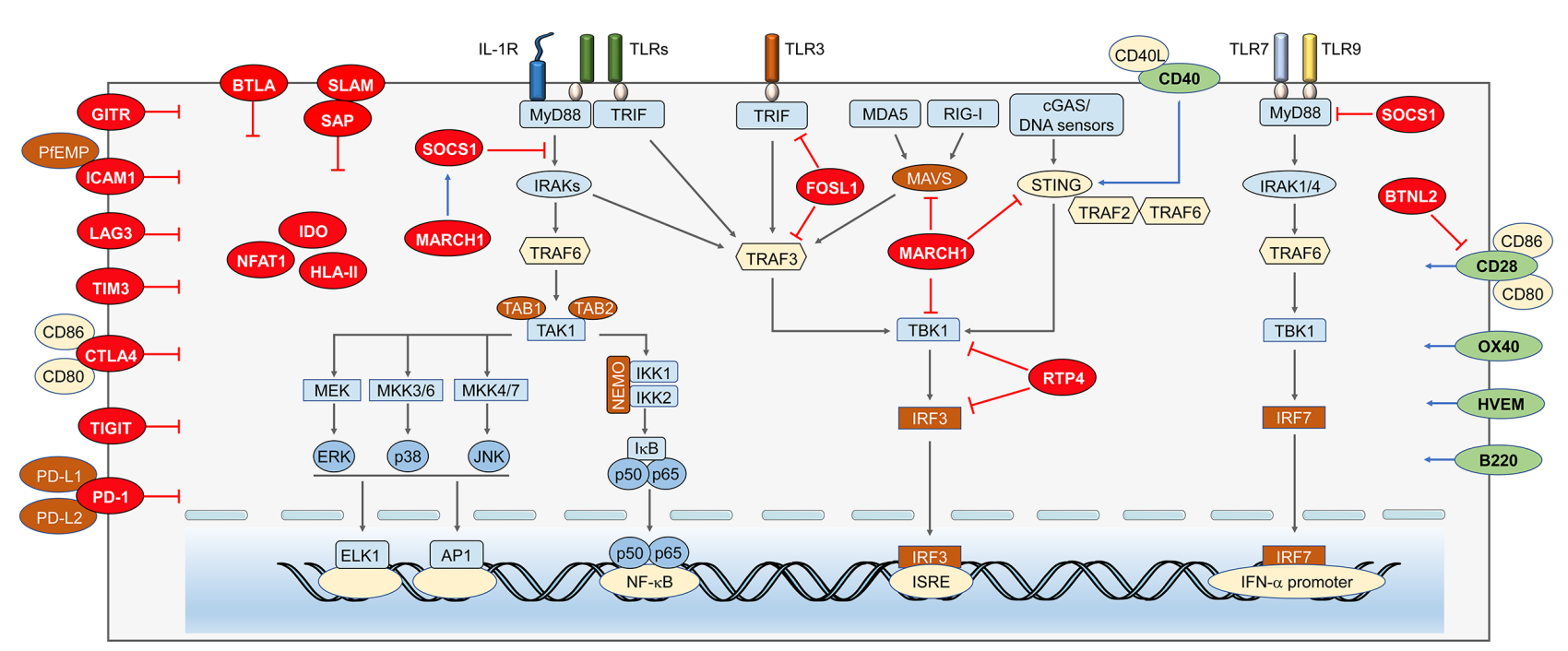

FIGURE 2 | Immune regulators in anti-malaria immunity. Anti-malaria immunity is tightly regulated by cytosolic and cell surface molecules at multiple levels. Negative regulators within cytosol. As a negative molecule binds to MyD88, SOCS-1 can not only suppress the NF- $\mathrm{KB}$ and MAPKs signaling, but also inhibits MyD88mediated IFN-I signaling. MARCH1 can reduce IFN-I through increasing expression of SOCS-1. Besides, its target proteins, MAVS, STING, and TBK1, possibly are degraded through ubiquitination. FOSL1 inhibits the K63 ubiquitination of TRAF3 and TRIF and disrupts TBK1/TRAF3/TRIF complexes formation, which results in reduced phosphorylation of IRF3 and suppresses IFN-I production. RTP4 inhibits the expression of TBK1 and IRF3 and/or activation by binding with TBK1 to reduce IFN-I production. Negative regulators on the cell membrane. Binding of ICAM1 and PfEMP leads to static adhesion of parasite and evades immune clearance. LAG3 inhibits T cell responses and antibody secreting B cell responses. CTLA-4 expressed on activated T cells could suppress the CD4 ${ }^{+}$Th and humoral immune responses. TIM3 can inhibit T lymphocytes, NK cells, and macrophages responses. TIGIT proteins mainly suppress the function of T cell and NK cell. The activation of PD-1 pathway dramatically inhibits TCR-mediated proliferation and function of T cells. Positive regulators on the cell membrane. CD40 could compete with STING to bind TRAF2/3 and/or TRAF6 to reduce STING ubiquitination, which leads to increased expression of IFN-I. CD28 can enhance CD4 ${ }^{+}$T cell responses, but the CD28-B7 signals can also be inhibited by BTNL2. OX40 enhances Plasmodium specific CD4 T cell activity. B220 expressed on the surface of B and T cells can help promoting the maturation of both $\mathrm{T}$ and $\mathrm{B}$ cell.

activation, which serves as a crucial second signal for $\mathrm{T}$ cell activation along with the MHC-TCR signaling (Carreno and Collins, 2002). CD28 could promote transcription signaling transduction, activation of cytokines or cytokine receptors, as well as activation and differentiation of naïve $\mathrm{CD} 4^{+}$and $\mathrm{CD} 8^{+} \mathrm{T}$ cells, to protect host from a variety of pathogens (Sharpe and Freeman, 2002; Elias et al., 2005; Butty et al., 2007; Cong et al., 2014; Niknam et al., 2017). During malaria infection, CD28 plays an essential role in enhancing $\mathrm{CD} 4^{+} \mathrm{T}$ cell responses and $\mathrm{CD} 4^{+} \mathrm{T}$ cell-driven antibody class switch (Falanga et al., 1984; Langhorne et al., 1989; Sanchez-Torres et al., 2001). Besides, CD28-CD80/ CD86 signals increase the survival and proliferation of $\gamma \delta \mathrm{T}$ cells to reduce severity of malaria infection (Dieli et al., 2001; D'ombrain et al., 2007; Ribot et al., 2012).

\section{OX40}

OX40 receptor, transiently expressed on T cells, is an important co-stimulatory molecule that interacts with TCRs and MHC complexes on APCs (Croft, 2010). Previous reports have denoted that OX40 promotes proliferation and survival of $\mathrm{T}$ cell, as well as differentiation of $\mathrm{CD} 4^{+} \mathrm{T}$ cells into Th1, Th2 and Tfh cell subsets; and reportedly reverses the hyperactivity of $\mathrm{CD} 4^{+} \mathrm{T}$ cell (Walker et al., 1999; Bansal-Pakala et al., 2001; Croft, 2010). Recent studies have demonstrated that OX40 would enhance Plasmodium specific $\mathrm{CD}^{+}$and $\mathrm{CD}^{+} \mathrm{T}$ cell activity, as well as parasite specific humoral immunity (Zander et al., 2015; Zander et al., 2017; Othman et al., 2018; Xia et al., 2018).

\section{Other Positive Regulators}

Herpes virus entry mediator (HVEM), a co-stimulatory receptor, expresses on the surface of B cells, T cells, endothelial cells and mast cells (Chang et al., 2005; Guo et al., 2015; Sibilano et al., 2016). Upon bacterial and viral infections, HVEM-mediated signaling pathway enhances $\mathrm{T}$ cell expansion and is necessary for persistence of memory $\mathrm{T}$ cell (Soroosh et al., 2011; Flynn et al., 2013; Steinberg et al., 2013; Desai et al., 2017). Recent findings of Muscate et al. indicated that HVEM is required to provide pro-survival signals for stabilizing $\mathrm{CD} 8^{+} \mathrm{T}$ effector cells during malaria infection (Muscate et al., 2018). During P. berghei ANKA infection, the HVEM-CD160 ligation is crucial for the delicate regulation of stimulatory and inhibitory signals in $\mathrm{CD}^{+} \mathrm{T}$ cells.

B220 is a high-molecular mass alternative splicing isoform of the tyrosine phosphatase CD45 (Renno et al., 1998). Its expression is found not only in B cell, including precursors, mature and memory B cells, but also in a subset activated T cells and pDCs (Marvel and Mayer, 1988; Hathcock et al., 1992; Renno et al., 1998; Rodig et al., 2005). Several studies have suggested that malaria exposure increased frequencies of B220, which is essential for promoting both $\mathrm{T}$ and $\mathrm{B}$ cells maturation 
(Asensi et al., 1990; Bakir et al., 2006; Niikura et al., 2008; Kanda et al., 2010; Bao et al., 2015; Ubillos et al., 2017).

\section{Negative Regulators \\ PD-1}

Unlike other CD28 family members, the expression of PD-1 (CD279) could be induced on activated monocytes, NK cells, DCs, myeloid cells, $\mathrm{CD} 4^{+} \mathrm{T}$ cells, $\mathrm{CD} 8^{+} \mathrm{T}$ cells, $\mathrm{B}$ cells, and a subset of thymocytes through TCR or BCR mediated signaling; as well as being augmented by stimulation of tumor necrosis factor (TNF) (Agata et al., 1996; Nakae et al., 2006; Okazaki and Honjo, 2006). The activation of PD-L1/PD-1 pathway dramatically inhibits TCR-mediated proliferation and function of $\mathrm{CD}^{+}$and $\mathrm{CD}^{+}$T cells (Freeman et al., 2000; Latchman et al., 2001; Rodig et al., 2003; Grosso et al., 2009). Several studies have demonstrated that pathogens including bacteria, viruses (such as HIV), protozoan parasites (including Plasmodium), and tumor cells could exploit above PD-1 inhibitory function on T cells to evade host adaptive immunity (Day et al., 2006; Horne-Debets et al., 2013; Gubin et al., 2014). In malaria infection, the number and function of parasite-specific $\mathrm{CD}^{+} \mathrm{T}$ cells (including Th1 and $\mathrm{Tfh}$ ), $\mathrm{CD}^{+}{ }^{+} \mathrm{T}$ cells, and memory $\mathrm{T}$ cells are significantly inhibited by PD-1 with decelerated parasite clearance (HorneDebets et al., 2013; Karunarathne et al., 2016; Liu T. et al., 2018; Pan et al., 2020). However, the inhibition of B cell function by PD-1 is controversial. During P. chabaudi infection, PD-1 elimination does not improve primary $B$ cell responses (Horne-Debets et al., 2013). In contrast, multiple studies have indicated that PD-1 deficiency substantially promoted expansion of GC B cells and humoral immunity in ITV (infection treatment vaccine)-immunized mice (Liu T. et al., 2015; Liu T. et al., 2018); and PD-1 elimination significantly increased long-lived plasma cells by P. berghei ANKA infection (Pan et al., 2020).

\section{SOCS1}

SOCS1 is one of the members of suppressors of cytokine signaling (SOCS) family, which regulates signal transduction pathways triggered by activation of cytokine and hormone receptors (Machado et al., 2006; Dimitriou et al., 2008). Socs $1^{-/-}$mice die within 3 weeks after birth, due to the high level of JAK/STATmediated inflammation, which could be significantly inhibited by SOCS1 (Naka et al., 1997; Starr et al., 1997; Naka et al., 1998; Starr et al., 1998), and this mice are highly susceptible to sepsis comparing to WT mice (Kinjyo et al., 2002; Nakagawa et al., 2002). Socs $1^{-/-}$ macrophages produce high amount of proinflammatory cytokines and nitric oxide after LPS and CpG stimulation. Moreover, SOCS1 seems to inhibit LPS- but not TNF-mediated NF- $\kappa B$ signaling through promoting the degradation of IRAK and NF- $\kappa B$ (Dimitriou et al., 2008).

Our studies have demonstrated that SOCS1 could interact with MyD88 to inhibit TLR7-MyD88-IRF7 dependent IFN-I signaling after lethal malaria infection (Yu et al., 2016; Yu et al., 2018; Cai and Yu, 2020). During malaria infection, Plasmodium gDNA and RNA activate cGAS/STING and MDA5/MAVS to induce IRF3-dependent SOCS1 production, respectively, which, in turn, bind to MyD88 to suppress MyD88-IRF7 dependent
IFN-I response, leading to fast parasite growth and host death (Yu et al., 2016). Furthermore, Plasmodium gDNA, RNA, and hemozoin also activate inflammasome signaling and lead to production of IL-1 $\beta$, which subsequently induces SOCS1 expression to inhibit MyD88 dependent IFN-I production ( $\mathrm{Yu}$ et al., 2018). Moreover, a recent study further illustrated the delicate cross-regulation between several IFN-I signaling pathways and inflammasome signaling pathways during lethal P. yoelii YM infection. Inflammasome-, MAVS-, and STINGmediated signaling pathways have diverse impacts on regulating MyD88-dependent IFN-I responses after P. yoelii YM infection; and the dosage of $P$. yoelii YM has significant effect on the differences of resistance among inflammasome, MAVS, and STING deficiency (Cai and Yu, 2020).

It has been reported that SOCS1 could simultaneously inhibit MyD88-dependent IFN-I production and downstream IFNdependent production of IFN- $\gamma$. However, SOCS1 deficiency could not protect host from infection in $\mathrm{Myd}_{88^{-/}}$mice, suggesting that SOCS1 controls the host resistance to malaria mainly through MyD88-mediated IFN-I production (Yu et al., 2018). Importantly, SOCS1 could be induced by IRF3-dependent signaling, LPS, and CpG DNA, as well as the downstream IFNstimulating pathway, indicating a negative-feedback regulatory mechanism to sustain its inhibitory function.

\section{FOSL1}

FOSL1 belongs to a gene family that encode proteins containing leucine zippers (Macchia et al., 2012), which are identified as regulators in trophoblast migration and invasion (Renaud et al., 2014). The FOSL1 contributes to several cellular processes, including proliferation, differentiation, and apoptosis via serving as a member of transcription factors and musculoaponeurotic fibrosarcoma (MAF) (Macchia et al., 2012). It has been reported that FOSL1 is a key downstream effector of the phosphatidylinositol 3-kinase (PI3K)/AKT signaling pathway to control Mmp9 gene expression and trophoblast lineages development (Kent et al., 2011). In addition, FOSL1 also plays a pivotal role in diverse cancers (Young and Colburn, 2006).

FOSL1 is normally expressed in the nucleus, while Cai et al. showed that cGAS-STING-, TRIF-, or RIG-I/MDA5-MAVSmediated IFN-I production could evoke the "translocation" of FOSL1 into the cytoplasm after iRBCs stimulations. The cytoplasmic FOSL1 inhibits the formation of TBK1/TRAF3/ TRIF complexes by suppressing K63 ubiquitination of TRAF3 and TRIF. The inhibition of FOSL1 on TBK1 complexes leads to suppression of IFN-I production (Cai et al., 2017). Hence, these reports identified FOSL1 as a negative regulator of IFN-I production during early infection and liver stages, resulting in fast parasite growth and host death (Liehl et al., 2014; Wu et al., 2014; Yu et al., 2016; Yu et al., 2018).

\section{MARCH1}

Membrane-associated ring-CH-type finger 1 (MARCH1) is a member of membrane-bound E3 ubiquitin ligases expressed mostly by DCs and B cells (Ohmura-Hoshino et al., 2006; Wu et al., 2020). The MARCH1 production is initiated by IL-10 after 
TLR4 and CD40 signaling (Galbas et al., 2012; Mittal et al., 2015). Besides, stimulating the monocyte-derived macrophages could enhance endogenous expression of MARCH1 (Zhang et al., 2019b). Previous studies, focusing on MARCH1 function, have shown that MARCH1 ubiquitinates CD86 and MHC-II molecules for degradation to down-regulate adaptive immunity; and may influence CD28, CTLA4, and PD-L1 signaling by regulating relative protein levels of $\mathrm{CD} 80 / \mathrm{CD} 86$ on antigenpresenting cells (APCs) (Ishido et al., 2009; Samji et al., 2014; Ablack et al., 2015).

$\mathrm{Wu}$ et al. have recently indicated that upon P. yoelii N67 or P. yoelii YM treatment, mice deficient in March1 had significant better survival rates than WT mice, indicating the negative function of MARCH1 in generating protective immunity against malaria infection (Liehl et al., 2014; Wu et al., 2014; Yu et al., 2016). Clustered with several ISGs in the Ts-eQTL analysis, MARCH1 deficient mice produce higher amount of IFN-I than WT mice in response to cGAMP and poly(I:C), accompany with increased protein levels of STING, MAVS, TRAF3 and TRAF6 in uninfected condition. However, reduced production level of IFNI was observed in MARCH1 deficient mice during early malaria infection. The mechanism by which MARCH1 regulates IFN-I remains obscure and several factors may include increased expression of genes encoding SOCS1, SOCS3, SIKE1, CACTIN, TRIM24, IL-10RA, USP18, and mir-21 that are known to suppress IFN-I responses (Huang et al., 2005; Yu and Hayward, 2010; Liu D. et al., 2015; Arimoto et al., 2017) and changes in DCs, Macs, and other cell populations can may also affect the levels of proteins critical for IFN-I production (Wu et al., 2020). In addition, MARCH1 deficiency significantly increased numbers of both $\mathrm{CD}^{+} 6^{+} \mathrm{DCs}$ population, which could promote CD86-CD28 interaction and $\mathrm{T}$ cell activation, leading to enhanced Th1-mediated response and IFN- $\gamma$ production (Wu et al., 2020).

\section{RTP4}

Receptor transporter family is known to promote cell surface expression of a group of G-protein-coupled receptors (GPCR). RTP4, a member of the RTP family, can be induced after viral infection (Nair S. R. et al., 2017; Dang et al., 2018). In addition, RTP4 plays an important role in mediating pain relief, bitterness, or odor sensing (Behrens et al., 2006; Decaillot et al., 2008). Su's group has suggested that the IFN-I and IFN-I pathways can induce RTP4 expression after parasite infection. Besides, RTP4 significantly inhibits IFN-I response through inhibition of TBK1 and IRF3 expression and activation by binding with TBK1 to reduce IFN-I production. Inhibition of RTP4 expression may help reduce parasitemia and help to alleviate symptoms of cerebral malaria (CM) and other diseases with neuropathology (He et al., 2020). Besides, Su's group also demonstrated that $P$. yoelii HECT-like E3 ubiquitin ligase ( $P y \mathrm{HEUL}$ ) encoding by malaria genome may indirectly affect host immune response and parasite infection by regulating the expression levels of proteins, such as merozoite surface protein 1 (MSP1) and/or cytoadherence-linked asexual gene 2 (CLAG2) (Nair S. C. et al., 2017).

\section{Other Negative Regulators}

Butyrophilin-like 2 (BTNL2) is a butyrophilin family member. Previous studies have demonstrated that BTNL2 inhibits T cells proliferation and is involved in a variety of autoimmune diseases (Lin et al., 2015; Tian et al., 2019). Besides, BTNL2 promotes Tregs generation through modifying B7/CD28 signaling (Swanson et al., 2013). Recent study has shown that BTNL2 also dampens $\mathrm{T}$ cells proliferation and activation in the $P$. berghei model of experimental cerebral malaria (ECM) (Subramaniam et al., 2015).

Indoleamine 2,3-dioxygenase (IDO) is induced by proinflammatory mediators, such as endotoxin and IFN- $\gamma$, in several tissues. IDO is a tryptophan-degrading enzyme; and has been identified an inhibitory function on proliferation of facultative intracellular pathogens and tumor cells (Taylor and Feng, 1991). In addition, IDO could suppress responses of T cells and promote tolerance (Mellor and Munn, 2004). Several studies have denoted that IDO is involved in CM (Medana et al., 2002; Medana et al., 2003; Mitchell et al., 2005).

Nuclear factor of activated T cell 1 (NFAT1) is a member of NFAT transcription factors, which are required for regulating the activation and differentiation of $\mathrm{T}$ cells (Macian, 2005). Multiple field reports, including malaria infection, have indicated that NFAT1-regulated gene expression is essential in efficient Treg-mediated $\mathrm{CD} 4^{+} \mathrm{T}$ cell suppression (Soto-Nieves et al., 2009; Shin et al., 2014; Ames et al., 2017; Kadziolka et al., 2017).

CD160 is expressed by NK, NKT, $\mathrm{CD}^{+} \mathrm{T}, \gamma \delta \mathrm{T}$, iIELs, ILC1, mast, and a minority of $\mathrm{CD} 4{ }^{+} \mathrm{T}$ cells (Maeda et al., 2005; Ortonne et al., 2011; Fuchs et al., 2013). The function of CD160 on $\mathrm{T}$ cells remains controversial, some studies have suggested that CD160 is a co-inhibitory molecule, while others have indicated that it has co-stimulative functions that promote proliferation and cytotoxicity of T cells, as well as inflammatory cytokine production (Le Bouteiller et al., 2002; Barakonyi et al., 2004; Cai et al., 2008). Strikingly, during malaria, CD160 is crucially involved in restricting $\mathrm{CD}^{+} \mathrm{T}$ cytotoxicity and IFN- $\gamma$ production (Muscate et al., 2018).

$\mathrm{B}$ and T lymphocyte attenuator (BTLA) (CD272), a coinhibitory receptor, is expressed by most leukocytes (Muscate et al., 2018). The BTLA is required for maintenance of peripheral tolerance by inhibiting lymphocytes activation. In malaria model, BTLA dampens innate immune responses and T/B cellmediated immune response to malaria infection (Sun et al., 2009; Vendel et al., 2009; Adler et al., 2011).

Once $\mathrm{T}$ cells are activated by CD28-CD80/CD86 signal, they enhance expression of cytotoxic $\mathrm{T}$ lymphocyte antigen-4 (CTLA4 , also named CD152), which is another receptor for CD80/ CD86. CTLA-4 is shown to be involved in maintenance of peripheral tolerance; inhibition of immune response against tumors and infectious diseases; as well as increased severity of autoimmune diseases (Gregor et al., 2004; Martins et al., 2004).

T-cell immunoglobulin- and mucin-domain-containing molecule 3 (TIM-3) is expressed by monocytes, macrophages, NK cells, DCs, and Th1 and Tc1 lymphocytes (Sakuishi et al., 2011). The binding of TIM-3 and galectin-9 negatively regulates 
T-cell and NK-cell activation in many diseases (Sabatos et al., 2003; Ju et al., 2010; Bi et al., 2011; Hou et al., 2012). Accumulated findings indicated that TIM-3 was responsible for inhibiting $\mathrm{T}$ lymphocytes $\left(\mathrm{CD} 4^{+} \mathrm{Th} 1 / \mathrm{Th} 2, \mathrm{CD} 8^{+}\right.$, and $\gamma \delta \mathrm{T}$ cells), NK cells, and macrophages responses to malaria treatment (Hou et al., 2016; Hou et al., 2017; Sabins et al., 2017; Schofield et al., 2017; Otterdal et al., 2018).

$\mathrm{T}$ cell immunoglobulin and ITIM domain (TIGIT) is expressed on the surface of NK cells and T cells ( $\mathrm{Yu}$ et al., 2009). It has reported that TIGIT as an inhibitor controls the function of NK cells, CD $4^{+} \mathrm{T}$ cells, and $\mathrm{CD} 8^{+} \mathrm{T}$ cells (Johnston et al., 2014). During P. berghei ANKA infection, the upregulation of TIGIT proteins results in inhibition on $\mathrm{T}$ and NK cells (Villegas-Mendez et al., 2016; Zhang et al., 2019a).

The Signaling Lymphocytic Activation Molecule (SLAM)Associated Protein (SAP), a small intracellular adaptor protein, could interact with the SLAM family and mediate downstream signaling of these receptors (Cannons et al., 2011). The deficient of SAP promotes the activation of Tfh and GC B cells, as well as IgG response against malaria infection (Perez-Mazliah et al., 2017).

Lymphocyte Activation Gene-3 (LAG-3) is expressed by many cells, including NK cells, T cells, B cells, and tumor infiltrating lymphocytes (Huang et al., 2004). As the $\mathrm{T}$ cell receptors, LAG-3 directly and indirectly induces transcriptional changes, which negatively modulates proliferation and proinflammatory cytokines expression by virus-specific $\mathrm{CD}^{+} \mathrm{T}$ cells (Barber et al., 2006; Blackburn et al., 2009). Butler et al. recently have shown that LAG-3 substantially inhibits T-cell responses and antibody secreting $\mathrm{B}$ cell responses to malaria infection (Butler et al., 2011).

Intracellular adhesion molecule 1(ICAM1, also named CD54) belongs to immunoglobulin superfamily; and is expressed by endothelial cells and leukocytes (Rowe et al., 2009). Binding of ICAM1 and malaria ligands, members of the PfEMP1 family, leads to static adhesion of parasite (Chattopadhyay et al., 2004; Springer et al., 2004). This adhesion occludes blood flow, leads to inflammation, and evades immune clearance (Lennartz et al., 2017; Lennartz et al., 2019).

The MHC [human leukocyte antigen (HLA) in humans] class II heterodimers are major participants in generating an immune response against microorganisms for providing exogenous peptides to activate and differentiate $\mathrm{CD} 4^{+} \mathrm{T}$ cells (Rothbard and Gefter, 1991). Previously, CD4 ${ }^{+}$Th1, Th2, and Th17 cells have been reported to be essential for coordinating the cellular and/or humoral response to clear pathogens, while the Treg cells downregulate those responses via secretion of suppressive cytokines or through direct cell-cell interactions (Surls et al., 2010; Ma et al., 2012; Issa et al., 2013). Importantly, during malaria infection, the HLA-II molecules evoke expansion and activation of Tregs to suppress antibody production by direct cell-cell interaction with B cells (Storti-Melo et al., 2012; Wijayalath et al., 2014).

Glucocorticoid-induced tumor necrosis factor receptor (GITR) constitutively expresses on cell surface of natural Tregs (Yagi et al., 2004; Belkaid and Rouse, 2005; Nocentini et al.,
2007). The interaction of GITR and agonist antibody or GITR ligand (GITRL) appears to abrogate suppressive activity of Tregs (Mchugh et al., 2002; Shimizu et al., 2002; Shevach and Stephens, 2006). However, engagement of GITR promotes proliferation and suppressive function of Tregs (Shevach and Stephens, 2006; Nocentini et al., 2007; Nishioka et al., 2008). In malaria infection, GITR is involved in the escape of parasites from host $\mathrm{T}$ cell immune responses (Hisaeda et al., 2005).

\section{CONCLUDING REMARKS}

Nearly 160 years post the discovery of Plasmodium in 1861, malaria is still a serious threat to global health that accounts for about 0.5 million deaths every year. Although significant progress has been done in most endemic area, eliminating malaria is still halted by emergence of drug resistance. Furthermore, the lack of an effective vaccine has been one of the major limiting factors in the prevention of malaria infection, which mainly due to the incomplete understanding of the underlying mechanism of host-parasite interactions.

During the past 10 years, stepwise progresses have been achieved in understanding the immune responses to malaria infection and their contribution to eliminating parasites. Yet, malaria infection triggers a systemic immune response, which in turn induces an increase in the production of inflammatory cytokines that lead to parasite elimination and/or immune pathology. Plasmodium infection induces host balanced responses in which activating signaling for anti-malaria states and promoting immunity counterbalanced by suppressive signaling that limit toxicity and enable chronic infection. Hence, a fine-tuned regulation of immune responses is crucial for developing protective immunity to effectively eliminate malaria parasites and preventing damage to host.

Plasmodium also exploits regulatory mechanisms to escape immune responses, including enhancing negative regulators and inhibiting positive regulators. We noticed that much more negative regulators are discovered than the positive regulators due to date, which may indicate that Plasmodium infection initiates multiple tools or signaling to evade host immune responses. Advances in these areas would aid the development of malaria vaccines and therapeutics that could selectively target pathogenic regulators while leaving defensive regulators intact. Here, we highlight our studies indicating the crucial role of early spike of IFN-I in protecting host from Plasmodium infection, and focus on discussing the regulatory network of immune responses against to malaria infection. Besides, we also emphasize our results demonstrating the importance of regulators mediated tune modulation of immune responses during malaria treatment. The search for more efficient vaccines and novel treatment strategies is a major objective in reducing the burden of malaria. Hence, any effort to control and eradicate malaria requires a better understanding of the contribution and regulation of immune responses to Plasmodium infection. In addition, new technologies, including whole genome-wide analysis in a single immune cell level and application of Mass Cytometry would offer 
promise for a more comprehensive investigation of immune responses and regulations in responses to malaria, and should facilitate the development of new effective vaccines and therapies.

\section{AUTHOR CONTRIBUTIONS}

$\mathrm{CC}$ wrote the manuscript. $\mathrm{ZH}$ drew the figures and wrote the manuscript. XY wrote the manuscript and supervised the entire project. All authors contributed to the article and approved the submitted version.

\section{FUNDING}

This work was supported by grants from the National Science Foundation of China (No. 81801579), Science and Technology Planning Project of Guangzhou (No. 201904010064), Guangdong Basic and Applied Basic Research Foundation (No. 2019B1515120033), Zhujiang Youth Scholar Funding, and the Start-up Fund for High-level Talents of Southern Medical University to XY. This work was also supported by the National Natural Science Foundation of China (No. 81960292) to CC.

\section{REFERENCES}

Abel, S., Luckheide, N., Westendorf, A. M., Geffers, R., Roers, A., Muller, W., et al. (2012). Strong impact of CD4+ Foxp3+ regulatory T cells and limited effect of T cell-derived IL-10 on pathogen clearance during Plasmodium yoelii infection. J. Immunol. 188, 5467-5477. doi: 10.4049/jimmunol.1102223

Ablack, J. N., Metz, P. J., Chang, J. T., Cantor, J. M., and Ginsberg, M. H. (2015). Ubiquitylation of CD98 limits cell proliferation and clonal expansion. J. Cell Sci. 128, 4273-4278. doi: 10.1242/jcs.178129

Adler, G., Steeg, C., Pfeffer, K., Murphy, T. L., Murphy, K. M., Langhorne, J., et al. (2011). B and T lymphocyte attenuator restricts the protective immune response against experimental malaria. J. Immunol. 187, 5310-5319. doi: 10.4049/jimmunol.1101456

Agata, Y., Kawasaki, A., Nishimura, H., Ishida, Y., Tsubata, T., Yagita, H., et al. (1996). Expression of the PD-1 antigen on the surface of stimulated mouse T and B lymphocytes. Int. Immunol. 8, 765-772. doi: 10.1093/intimm/8.5.765

Alanine, D. G. W., Quinkert, D., Kumarasingha, R., Mehmood, S., Donnellan, F. R., Minkah, N. K., et al. (2019). Human Antibodies that Slow Erythrocyte Invasion Potentiate Malaria-Neutralizing Antibodies. Cell 178, 216-228.e221. doi: 10.1016/j.cell.2019.05.025

Aliprandini, E., Tavares, J., Panatieri, R. H., Thiberge, S., Yamamoto, M. M., Silvie, O., et al. (2018). Cytotoxic anti-circumsporozoite antibodies target malaria sporozoites in the host skin. Nat. Microbiol. 3, 1224-1233. doi: 10.1038/ s41564-018-0254-Z

Ames, R. Y., Ting, L. M., Gendlina, I., Kim, K., and Macian, F. (2017). The Transcription Factor NFAT1 Participates in the Induction of CD4(+) T Cell Functional Exhaustion during Plasmodium yoelii Infection. Infect. Immun. 85, e00364-17. doi: 10.1128/IAI.00364-17

Amino, R., Thiberge, S., Martin, B., Celli, S., Shorte, S., Frischknecht, F., et al. (2006). Quantitative imaging of Plasmodium transmission from mosquito to mammal. Nat. Med. 12, 220-224. doi: 10.1038/nm1350

Arama, C., and Troye-Blomberg, M. (2014). The path of malaria vaccine development: challenges and perspectives. J. Intern. Med. 275, 456-466. doi: 10.1111/joim. 12223

Arimoto, K. I., Lochte, S., Stoner, S. A., Burkart, C., Zhang, Y., Miyauchi, S., et al. (2017). STAT2 is an essential adaptor in USP18-mediated suppression of type I interferon signaling. Nat. Struct. Mol. Biol. 24, 279-289. doi: 10.1038/ nsmb.3378

Artavanis-Tsakonas, K., and Riley, E. M. (2002). Innate immune response to malaria: rapid induction of IFN-gamma from human NK cells by live Plasmodium falciparum-infected erythrocytes. J. Immunol. 169, 2956-2963. doi: 10.4049/jimmunol.169.6.2956

Asensi, V., Himeno, K., Kawamura, I., Sakumoto, M., and Nomoto, K. (1990). In vivo treatment with anti B-220 monoclonal antibody affects $\mathrm{T}$ and B cell differentiation. Clin. Exp. Immunol. 80, 268-273. doi: 10.1111/j.13652249.1990.tb05246.x

Baccarella, A., Fontana, M. F., Chen, E. C., and Kim, C. C. (2013). Toll-like receptor 7 mediates early innate immune responses to malaria. Infect. Immun. 81, 4431-4442. doi: 10.1128/IAI.00923-13

Baker, V. S., Imade, G. E., Molta, N. B., Tawde, P., Pam, S. D., Obadofin, M. O., et al. (2008). Cytokine-associated neutrophil extracellular traps and antinuclear

antibodies in Plasmodium falciparum infected children under six years of age. Malar. J. 7, 41. doi: 10.1186/1475-2875-7-41

Bakir, H. Y., Tomiyama-Miyaji, C., Watanabe, H., Nagura, T., Kawamura, T., Sekikawa, H., et al. (2006). Reasons why DBA/2 mice are resistant to malarial infection: expansion of CD3int B220+ gammadelta $\mathrm{T}$ cells with doublenegative CD4- CD8- phenotype in the liver. Immunology 117, 127-135. doi: 10.1111/j.1365-2567.2005.02273.x

Bansal, G. P., Weinstein, C. S., and Kumar, N. (2016). Insight into phagocytosis of mature sexual (gametocyte) stages of Plasmodium falciparum using a human monocyte cell line. Acta Trop. 157,96-101. doi: 10.1016/j.actatropica.2016.01.033

Bansal-Pakala, P., Jember, A. G., and Croft, M. (2001). Signaling through OX40 (CD134) breaks peripheral T-cell tolerance. Nat. Med. 7, 907-912. doi: $10.1038 / 90942$

Bao, L. Q., Nhi, D. M., Huy, N. T., Kikuchi, M., Yanagi, T., Hamano, S., et al. (2015). Splenic CD11c+ cells derived from semi-immune mice protect naive mice against experimental cerebral malaria. Malar. J. 14, 23. doi: 10.1186/ s12936-014-0533-y

Barakonyi, A., Rabot, M., Marie-Cardine, A., Aguerre-Girr, M., Polgar, B., Schiavon, V., et al. (2004). Cutting edge: engagement of CD160 by its HLA$\mathrm{C}$ physiological ligand triggers a unique cytokine profile secretion in the cytotoxic peripheral blood NK cell subset. J. Immunol. 173, 5349-5354. doi: 10.4049/jimmunol.173.9.5349

Baratin, M., Roetynck, S., Pouvelle, B., Lemmers, C., Viebig, N. K., Johansson, S., et al. (2007). Dissection of the role of PfEMP1 and ICAM-1 in the sensing of Plasmodium-falciparum-infected erythrocytes by natural killer cells. PloS One 2, e228. doi: 10.1371/journal.pone.0000228

Barbalat, R., Ewald, S. E., Mouchess, M. L., and Barton, G. M. (2011). Nucleic acid recognition by the innate immune system. Annu. Rev. Immunol. 29, 185-214. doi: 10.1146/annurev-immunol-031210-101340

Barber, D. L., Wherry, E. J., Masopust, D., Zhu, B., Allison, J. P., Sharpe, A. H., et al. (2006). Restoring function in exhausted CD8 T cells during chronic viral infection. Nature 439, 682-687. doi: 10.1038/nature04444

Barnett, B. E., Staupe, R. P., Odorizzi, P. M., Palko, O., Tomov, V. T., Mahan, A. E., et al. (2016). Cutting Edge: B Cell-Intrinsic T-bet Expression Is Required To Control Chronic Viral Infection. J. Immunol. 197, 1017-1022. doi: 10.4049/ jimmunol.1500368

Battle, K. E., Guerra, C. A., Golding, N., Duda, K. A., Cameron, E., Howes, R. E., et al. (2015). Global database of matched Plasmodium falciparum and P. vivax incidence and prevalence records from 1985-2013. Sci. Data 2, 150012. doi: 10.1038/sdata.2015.12

Behrens, M., Bartelt, J., Reichling, C., Winnig, M., Kuhn, C., and Meyerhof, W. (2006). Members of RTP and REEP gene families influence functional bitter taste receptor expression. J. Biol. Chem. 281, 20650-20659. doi: 10.1074/ jbc.M513637200

Belkaid, Y., and Rouse, B. T. (2005). Natural regulatory T cells in infectious disease. Nat. Immunol. 6, 353-360. doi: 10.1038/ni1181

Bennett, S. R., Carbone, F. R., Karamalis, F., Flavell, R. A., Miller, J. F., and Heath, W. R. (1998). Help for cytotoxic-T-cell responses is mediated by CD40 signalling. Nature 393, 478-480. doi: 10.1038/30996

Benveniste, E. N., Nguyen, V. T., and Wesemann, D. R. (2004). Molecular regulation of CD40 gene expression in macrophages and microglia. Brain Behav. Immun. 18, 7-12. doi: 10.1016/j.bbi.2003.09.001 
Bi, S., Hong, P. W., Lee, B., and Baum, L. G. (2011). Galectin-9 binding to cell surface protein disulfide isomerase regulates the redox environment to enhance T-cell migration and HIV entry. Proc. Natl. Acad. Sci. U.S.A. 108, 1065010655. doi: $10.1073 /$ pnas. 1017954108

Blackburn, S. D., Shin, H., Haining, W. N., Zou, T., Workman, C. J., Polley, A., et al. (2009). Coregulation of CD8+ T cell exhaustion by multiple inhibitory receptors during chronic viral infection. Nat. Immunol. 10, 29-37. doi: 10.1038/ni.1679

Butler, N. S., Moebius, J., Pewe, L. L., Traore, B., Doumbo, O. K., Tygrett, L. T., et al. (2011). Therapeutic blockade of PD-L1 and LAG-3 rapidly clears established blood-stage Plasmodium infection. Nat. Immunol. 13, 188-195. doi: $10.1038 /$ ni.2180

Butty, V., Roy, M., Sabeti, P., Besse, W., Benoist, C., and Mathis, D. (2007). Signatures of strong population differentiation shape extended haplotypes across the human CD28, CTLA4, and ICOS costimulatory genes. Proc. Natl. Acad. Sci. U.S.A. 104, 570-575. doi: 10.1073/pnas.0610124104

Cai, C., and Yu, X. (2020). A mathematic model to reveal delicate cross-regulation between MAVS/STING, inflammasome and MyD88-dependent type I interferon signalling. J. Cell Mol. Med. 24, 11535-11545. doi: 10.1111/ jcmm.15768

Cai, G., Anumanthan, A., Brown, J. A., Greenfield, E. A., Zhu, B., and Freeman, G. J. (2008). CD160 inhibits activation of human CD4+ T cells through interaction with herpesvirus entry mediator. Nat. Immunol. 9, 176-185. doi: 10.1038/nil554

Cai, B., Wu, J., Yu, X., Su, X. Z., and Wang, R. F. (2017). FOSL1 Inhibits Type I Interferon Responses to Malaria and Viral Infections by Blocking TBK1 and TRAF3/TRIF Interactions. mBio 8, e02161-16. doi: 10.1128/mBio.02161-16

Cannons, J. L., Tangye, S. G., and Schwartzberg, P. L. (2011). SLAM family receptors and SAP adaptors in immunity. Annu. Rev. Immunol. 29, 665-705. doi: 10.1146/annurev-immunol-030409-101302

Carlring, J., Altaher, H. M., Clark, S., Chen, X., Latimer, S. L., Jenner, T., et al. (2011). CD154-CD40 interactions in the control of murine B cell hematopoiesis. J. Leukoc. Biol. 89, 697-706. doi: 10.1189/jlb.0310179

Carreno, B. M., and Collins, M. (2002). The B7 family of ligands and its receptors: new pathways for costimulation and inhibition of immune responses. Annu. Rev. Immunol. 20, 29-53. doi: 10.1146/annurev.immunol.20.091101.091806

Chan, J. A., De Labastida Rivera, F., Loughland, J., Engel, J. A., Lee, H. J., Sheelanair, A., et al. (2020). Th2-like T-follicular helper cells promote functional antibody production during Plasmodium falciparum infection. bioRxiv. doi: 10.1101/2020.05.18.101048

Chang, Y. H., Hsieh, S. L., Chao, Y., Chou, Y. C., and Lin, W. W. (2005). Proinflammatory effects of LIGHT through HVEM and LTbetaR interactions in cultured human umbilical vein endothelial cells. J. BioMed. Sci. 12, 363-375. doi: $10.1007 / \mathrm{s} 11373-005-1360-5$

Chattopadhyay, R., Taneja, T., Chakrabarti, K., Pillai, C. R., and Chitnis, C. E. (2004). Molecular analysis of the cytoadherence phenotype of a Plasmodium falciparum field isolate that binds intercellular adhesion molecule-1. Mol. Biochem. Parasitol. 133, 255-265. doi: 10.1016/j.molbiopara.2003.08.014

Chen, Q., Amaladoss, A., Ye, W., Liu, M., Dummler, S., Kong, F., et al. (2014). Human natural killer cells control Plasmodium falciparum infection by eliminating infected red blood cells. Proc. Natl. Acad. Sci. U.S.A. 111, 14791484. doi: $10.1073 /$ pnas. 1323318111

Chua, C. L., Brown, G., Hamilton, J. A., Rogerson, S., and Boeuf, P. (2013). Monocytes and macrophages in malaria: protection or pathology? Trends Parasitol. 29, 26-34. doi: 10.1016/j.pt.2012.10.002

Clark, I. A., Alleva, L. M., Budd, A. C., and Cowden, W. B. (2008). Understanding the role of inflammatory cytokines in malaria and related diseases. Travel Med. Infect. Dis. 6, 67-81. doi: 10.1016/j.tmaid.2007.07.002

Coban, C., Ishii, K. J., Kawai, T., Hemmi, H., Sato, S., Uematsu, S., et al. (2005). Toll-like receptor 9 mediates innate immune activation by the malaria pigment hemozoin. J. Exp. Med. 201, 19-25. doi: 10.1084/jem.20041836

Coban, C., Igari, Y., Yagi, M., Reimer, T., Koyama, S., Aoshi, T., et al. (2010). Immunogenicity of whole-parasite vaccines against Plasmodium falciparum involves malarial hemozoin and host TLR9. Cell Host. Microbe 7, 50-61. doi: 10.1016/j.chom.2009.12.003

Colborn, J. M., Ylostalo, J. H., Koita, O. A., Cisse, O. H., and Krogstad, D. J. (2015). Human Gene Expression in Uncomplicated Plasmodium falciparum Malaria. J. Immunol. Res. 2015, 162639. doi: 10.1155/2015/162639
Combes, V., Taylor, T. E., Juhan-Vague, I., Mege, J. L., Mwenechanya, J., Tembo, M., et al. (2004). Circulating endothelial microparticles in malawian children with severe falciparum malaria complicated with coma. JAMA 291, 2542-2544. doi: 10.1001/jama.291.21.2542-b

Cong, J., Zhang, S., and Gao, X. (2014). Quantitative assessment of the associations between CD28 T > C polymorphism (rs3116496) and cancer risk. Tumour Biol. 35, 9195-9200. doi: 10.1007/s13277-014-2204-6

Coomes, S. M., Pelly, V. S., Kannan, Y., Okoye, I. S., Czieso, S., Entwistle, L. J., et al. (2015). IFNgamma and IL-12 Restrict Th2 Responses during Helminth/ Plasmodium Co-Infection and Promote IFNgamma from Th2 Cells. PloS Pathog. 11, e1004994. doi: 10.1371/journal.ppat.1004994

Couper, K. N., Blount, D. G., Wilson, M. S., Hafalla, J. C., Belkaid, Y., Kamanaka, M., et al. (2008). IL-10 from CD4CD25Foxp3CD127 adaptive regulatory T cells modulates parasite clearance and pathology during malaria infection. PloS Pathog. 4, e1000004. doi: 10.1371/journal.ppat.1000004

Couper, K. N., Barnes, T., Hafalla, J. C., Combes, V., Ryffel, B., Secher, T., et al. (2010). Parasite-derived plasma microparticles contribute significantly to malaria infection-induced inflammation through potent macrophage stimulation. PloS Pathog. 6, e1000744. doi: 10.1371/journal.ppat.1000744

Croft, M. (2010). Control of immunity by the TNFR-related molecule OX40 (CD134). Annu. Rev. Immunol. 28, 57-78. doi: 10.1146/annurev-immunol030409-101243

Crompton, P. D., Kayala, M. A., Traore, B., Kayentao, K., Ongoiba, A., Weiss, G. E., et al. (2010). A prospective analysis of the $\mathrm{Ab}$ response to Plasmodium falciparum before and after a malaria season by protein microarray. Proc. Natl. Acad. Sci. U.S.A. 107, 6958-6963. doi: 10.1073/pnas.1001323107

Crotty, S. (2019). T Follicular Helper Cell Biology: A Decade of Discovery and Diseases. Immunity 50, 1132-1148. doi: 10.1016/j.immuni.2019.04.011

Da Silva, H. B., De Salles, E. M., Panatieri, R. H., Boscardin, S. B., RodriguezMalaga, S. M., Alvarez, J. M., et al. (2013). IFN-gamma-induced priming maintains long-term strain-transcending immunity against blood-stage Plasmodium chabaudi malaria. J. Immunol. 191, 5160-5169. doi: 10.4049/ jimmunol.1300462

Dale, D. C., Boxer, L., and Liles, W. C. (2008). The phagocytes: neutrophils and monocytes. Blood 112, 935-945. doi: 10.1182/blood-2007-12-077917

Dang, W., Xu, L., Yin, Y., Chen, S., Wang, W., Hakim, M. S., et al. (2018). IRF-1, RIG-I and MDA5 display potent antiviral activities against norovirus coordinately induced by different types of interferons. Antiviral Res. 155, 4859. doi: 10.1016/j.antiviral.2018.05.004

Day, C. L., Kaufmann, D. E., Kiepiela, P., Brown, J. A., Moodley, E. S., Reddy, S., et al. (2006). PD-1 expression on HIV-specific T cells is associated with T-cell exhaustion and disease progression. Nature 443, 350-354. doi: 10.1038/ nature 05115

Decaillot, F. M., Rozenfeld, R., Gupta, A., and Devi, L. A. (2008). Cell surface targeting of mu-delta opioid receptor heterodimers by RTP4. Proc. Natl. Acad. Sci. U.S.A. 105, 16045-16050. doi: 10.1073/pnas.0804106105

Deroost, K., Pham, T. T., Opdenakker, G., and Van Den Steen, P. E. (2016). The immunological balance between host and parasite in malaria. FEMS Microbiol. Rev. 40, 208-257. doi: 10.1093/femsre/fuv046

Desai, P., Abboud, G., Stanfield, J., Thomas, P. G., Song, J., Ware, C. F., et al. (2017). HVEM Imprints Memory Potential on Effector CD8 T Cells Required for Protective Mucosal Immunity. J. Immunol. 199, 2968-2975. doi: 10.4049/ jimmunol.1700959

Dieli, F., Troye-Blomberg, M., Farouk, S. E., Sireci, G., and Salerno, A. (2001). Biology of gammadelta T cells in tuberculosis and malaria. Curr. Mol. Med. 1, 437-446. doi: 10.2174/1566524013363627

Dimitriou, I. D., Clemenza, L., Scotter, A. J., Chen, G., Guerra, F. M., and Rottapel, R. (2008). Putting out the fire: coordinated suppression of the innate and adaptive immune systems by SOCS1 and SOCS3 proteins. Immunol. Rev. 224, 265-283. doi: 10.1111/j.1600-065X.2008.00659.x

Ding, H., Yang, X., and Wei, Y. (2018). Fusion Proteins of NKG2D/NKG2DL in Cancer Immunotherapy. Int. J. Mol. Sci. 19 (1), 177. doi: 10.3390/ijms19010177

Doolan, D. L., Hoffman, S. L., Southwood, S., Wentworth, P. A., Sidney, J., Chesnut, R. W., et al. (1997). Degenerate cytotoxic T cell epitopes from P. falciparum restricted by multiple HLA-A and HLA-B supertype alleles. Immunity 7, 97-112. doi: 10.1016/S1074-7613(00)80513-0

Doolan, D. L., Southwood, S., Freilich, D. A., Sidney, J., Graber, N. L., Shatney, L., et al. (2003). Identification of Plasmodium falciparum antigens by antigenic 
analysis of genomic and proteomic data. Proc. Natl. Acad. Sci. U.S.A. 100, 9952-9957. doi: 10.1073/pnas.1633254100

Doolan, D. L., Dobano, C., and Baird, J. K. (2009). Acquired immunity to malaria. Clin. Microbiol. Rev. 22, 13-36. doi: 10.1128/CMR.00025-08

D'ombrain, M. C., Hansen, D. S., Simpson, K. M., and Schofield, L. (2007). gammadelta-T cells expressing NK receptors predominate over NK cells and conventional $\mathrm{T}$ cells in the innate IFN-gamma response to Plasmodium falciparum malaria. Eur. J. Immunol. 37, 1864-1873. doi: 10.1002/ eji.200636889

Dupre-Crochet, S., Erard, M., and Nubetae, O. (2013). ROS production in phagocytes: why, when, and where? J. Leukoc. Biol. 94, 657-670. doi: 10.1189/jlb.1012544

Elgueta, R., Benson, M. J., De Vries, V. C., Wasiuk, A., Guo, Y., and Noelle, R. J. (2009). Molecular mechanism and function of CD40/CD40L engagement in the immune system. Immunol. Rev. 229, 152-172. doi: 10.1111/j.1600065X.2009.00782.x

Elias, R. M., Sardinha, L. R., Bastos, K. R., Zago, C. A., Da Silva, A. P., Alvarez, J. M., et al. (2005). Role of CD28 in polyclonal and specific T and B cell responses required for protection against blood stage malaria. J. Immunol. 174, 790-799. doi: 10.4049/jimmunol.174.2.790

Falanga, P. B., Franco Da Silveira, J. F., and Pereira Da Silva, L. (1984). Protective immune response to Plasmodium chabaudi, developed by mice after drug controlled infection or vaccination with parasite extracts: analysis of stage specific antigens from the asexual blood cycle. Parasite Immunol. 6, 529-543. doi: 10.1111/j.1365-3024.1984.tb00823.x

Ferreira, A., Marguti, I., Bechmann, I., Jeney, V., Chora, A., Palha, N. R., et al. (2011). Sickle hemoglobin confers tolerance to Plasmodium infection. Cell 145, 398-409. doi: 10.1016/j.cell.2011.03.049

Figueiredo, R. T., Fernandez, P. L., Mourao-Sa, D. S., Porto, B. N., Dutra, F. F., Alves, L. S., et al. (2007). Characterization of heme as activator of Toll-like receptor 4. J. Biol. Chem. 282, 20221-20229. doi: 10.1074/jbc.M610737200

Figueiredo, M. M., Costa, P. A. C., Diniz, S. Q., Henriques, P. M., Kano, F. S., Tada, M. S., et al. (2017). T follicular helper cells regulate the activation of $B$ lymphocytes and antibody production during Plasmodium vivax infection. PloS Pathog. 13, e1006484. doi: 10.1371/journal.ppat.1006484

Flynn, R., Hutchinson, T., Murphy, K. M., Ware, C. F., Croft, M., and SalekArdakani, S. (2013). CD8 T cell memory to a viral pathogen requires trans cosignaling between HVEM and BTLA. PloS One 8, e77991. doi: 10.1371/ journal.pone.0077991

Fowkes, F. J., Richards, J. S., Simpson, J. A., and Beeson, J. G. (2010). The relationship between anti-merozoite antibodies and incidence of Plasmodium falciparum malaria: A systematic review and meta-analysis. PloS Med. 7, e1000218. doi: 10.1371/journal.pmed.1000218

Freeman, G. J., Long, A. J., Iwai, Y., Bourque, K., Chernova, T., Nishimura, H., et al. (2000). Engagement of the PD-1 immunoinhibitory receptor by a novel B7 family member leads to negative regulation of lymphocyte activation. J. Exp. Med. 192, 1027-1034. doi: 10.1084/jem.192.7.1027

Freitas Do Rosario, A. P., Lamb, T., Spence, P., Stephens, R., Lang, A., Roers, A., et al. (2012). IL-27 promotes IL-10 production by effector Th1 CD $4+\mathrm{T}$ cells: a critical mechanism for protection from severe immunopathology during malaria infection. J. Immunol. 188, 1178-1190. doi: 10.4049/jimmunol.1102755

Fuchs, A., Vermi, W., Lee, J. S., Lonardi, S., Gilfillan, S., Newberry, R. D., et al. (2013). Intraepithelial type 1 innate lymphoid cells are a unique subset of IL12- and IL-15-responsive IFN-gamma-producing cells. Immunity 38, 769-781. doi: $10.1016 /$ j.immuni.2013.02.010

Galbas, T., Steimle, V., Lapointe, R., Ishido, S., and Thibodeau, J. (2012). MARCH1 down-regulation in IL-10-activated B cells increases MHC class II expression. Cytokine 59, 27-30. doi: 10.1016/j.cyto.2012.03.015

Gallego-Delgado, J., Ty, M., Orengo, J. M., Van De Hoef, D., and Rodriguez, A. (2014). A surprising role for uric acid: the inflammatory malaria response. Curr. Rheumatol. Rep. 16, 401. doi: 10.1007/s11926-013-0401-8

Gazzinelli, R. T., and Denkers, E. Y. (2006). Protozoan encounters with Toll-like receptor signalling pathways: implications for host parasitism. Nat. Rev. Immunol. 6, 895-906. doi: 10.1038/nri1978

Gazzinelli, R. T., Kalantari, P., Fitzgerald, K. A., and Golenbock, D. T. (2014). Innate sensing of malaria parasites. Nat. Rev. Immunol. 14, 744-757. doi: $10.1038 /$ nri3742
Gowda, N. M., Wu, X., and Gowda, D. C. (2012). TLR9 and MyD88 are crucial for the development of protective immunity to malaria. J. Immunol. 188, 50735085. doi: 10.4049/jimmunol.1102143

Gramaglia, I., Velez, J., Combes, V., Grau, G. E., Wree, M., and Van Der Heyde, H. C. (2017). Platelets activate a pathogenic response to blood-stage Plasmodium infection but not a protective immune response. Blood 129, 1669-1679. doi: 10.1182/blood-2016-08-733519

Grassi, B., Bignami, A., and Bastianelli, G. (1899). Medical Zoology: Further Researches upon the Cycle of Human Malaria in the Body of the Mosquito. Ind. Med. Gaz. 34, 104-107.

Gregor, P. D., Wolchok, J. D., Ferrone, C. R., Buchinshky, H., Guevara-Patino, J. A., Perales, M. A., et al. (2004). CTLA-4 blockade in combination with xenogeneic DNA vaccines enhances T-cell responses, tumor immunity and autoimmunity to self antigens in animal and cellular model systems. Vaccine 22, 1700-1708. doi: 10.1016/j.vaccine.2003.10.048

Griffith, J. W., Sun, T., Mcintosh, M. T., and Bucala, R. (2009). Pure Hemozoin is inflammatory in vivo and activates the NALP3 inflammasome via release of uric acid. J. Immunol. 183, 5208-5220. doi: 10.4049/jimmunol.0713552

Gross, J. A., Callas, E., and Allison, J. P. (1992). Identification and distribution of the costimulatory receptor CD28 in the mouse. J. Immunol. 149, 380-388.

Grosso, J. F., Goldberg, M. V., Getnet, D., Bruno, T. C., Yen, H. R., Pyle, K. J., et al. (2009). Functionally distinct LAG-3 and PD-1 subsets on activated and chronically stimulated CD8 T cells. J. Immunol. 182, 6659-6669. doi: 10.4049/jimmunol.0804211

Gubin, M. M., Zhang, X., Schuster, H., Caron, E., Ward, J. P., Noguchi, T., et al. (2014). Checkpoint blockade cancer immunotherapy targets tumour-specific mutant antigens. Nature 515, 577-581. doi: 10.1038/nature13988

Guo, H., Pang, K., Wei, Y., Yi, C., and Wu, X. (2015). Herpes virus entry mediator in human corneal epithelial cells modulates the production of inflammatory cytokines in response to HSV type 1 challenge. Ophthalmic Res. 54, 128-134. doi: $10.1159 / 000437209$

Gupta, S., Snow, R. W., Donnelly, C. A., Marsh, K., and Newbold, C. (1999). Immunity to non-cerebral severe malaria is acquired after one or two infections. Nat. Med. 5, 340-343. doi: 10.1038/6560

Gwyer Findlay, E., Villegas-Mendez, A., O'regan, N., De Souza, J. B., Grady, L. M., Saris, C. J., et al. (2014). IL-27 receptor signaling regulates memory CD4+ T cell populations and suppresses rapid inflammatory responses during secondary malaria infection. Infect. Immun. 82, 10-20. doi: 10.1128/IAI.01091-13

Hansen, D. S., and Schofield, L. (2010). Natural regulatory T cells in malaria: host or parasite allies? PloS Pathog. 6, e1000771. doi: 10.1371/journal.ppat.1000771

Haque, A., Best, S. E., Ammerdorffer, A., Desbarrieres, L., De Oca, M. M., Amante, F. H., et al. (2011). Type I interferons suppress CD4(+) T-cell-dependent parasite control during blood-stage Plasmodium infection. Eur. J. Immunol. 41, 2688-2698. doi: 10.1002/eji.201141539

Haque, A., Best, S. E., Montes De Oca, M., James, K. R., Ammerdorffer, A., Edwards, C. L., et al. (2014). Type I IFN signaling in CD8- DCs impairs Th1dependent malaria immunity. J. Clin. Invest. 124, 2483-2496. doi: 10.1172/ JCI70698

Hathcock, K. S., Hirano, H., Murakami, S., and Hodes, R. J. (1992). CD45 expression by B cells. Expression of different CD45 isoforms by subpopulations of activated B cells. J. Immunol. 149, 2286-2294.

He, X., Ashbrook, A. W., Du, Y., Wu, J., Hoffmann, H. H., Zhang, C., et al. (2020). RTP4 inhibits IFN-I response and enhances experimental cerebral malaria and neuropathology. Proc. Natl. Acad. Sci. U.S.A. 117, 19465-19474. doi: 10.1073/ pnas. 2006492117

Hisaeda, H., Hamano, S., Mitoma-Obata, C., Tetsutani, K., Imai, T., Waldmann, H., et al. (2005). Resistance of regulatory $\mathrm{T}$ cells to glucocorticoid-induced [corrected] TNFR family-related protein (GITR) during Plasmodium yoelii infection. Eur. J. Immunol. 35, 3516-3524. doi: 10.1002/eji.200526073

Hoffman, S. L., Oster, C. N., Plowe, C. V., Woollett, G. R., Beier, J. C., Chulay, J. D., et al. (1987). Naturally acquired antibodies to sporozoites do not prevent malaria: vaccine development implications. Science 237, 639-642. doi: 10.1126/ science. 3299709

Hommel, M., Chan, J. A., Umbers, A. J., Langer, C., Rogerson, S. J., Smith, J. D., et al. (2018). Evaluating antibody functional activity and strain-specificity of vaccine candidates for malaria in pregnancy using in vitro phagocytosis assays. Parasit. Vectors 11, 69. doi: 10.1186/s13071-018-2653-7 
Hopp, C. S., and Sinnis, P. (2015). The innate and adaptive response to mosquito saliva and Plasmodium sporozoites in the skin. Ann. N Y Acad. Sci. 1342, $37-$ 43. doi: $10.1111 /$ nyas. 12661

Horne-Debets, J. M., Faleiro, R., Karunarathne, D. S., Liu, X. Q., Lineburg, K. E., Poh, C. M., et al. (2013). PD-1 dependent exhaustion of CD8+ T cells drives chronic malaria. Cell Rep. 5, 1204-1213. doi: 10.1016/j.celrep.2013.11.002

Horowitz, A., Newman, K. C., Evans, J. H., Korbel, D. S., Davis, D. M., and Riley, E. M. (2010). Cross-talk between T cells and NK cells generates rapid effector responses to Plasmodium falciparum-infected erythrocytes. J. Immunol. 184, 6043-6052. doi: 10.4049/jimmunol.1000106

Hou, N., Zhao, D., Liu, Y., Gao, L., Liang, X., Liu, X., et al. (2012). Increased expression of $\mathrm{T}$ cell immunoglobulin- and mucin domain-containing molecule-3 on natural killer cells in atherogenesis. Atherosclerosis 222, 6773. doi: 10.1016/j.atherosclerosis.2012.02.009

Hou, N., Zou, Y., Piao, X., Liu, S., Wang, L., Li, S., et al. (2016). T-Cell Immunoglobulin- and Mucin-Domain-Containing Molecule 3 Signaling Blockade Improves Cell-Mediated Immunity Against Malaria. J. Infect. Dis. 214, 1547-1556. doi: 10.1093/infdis/jiw428

Hou, N., Jiang, N., Zou, Y., Piao, X., Liu, S., Li, S., et al. (2017). Down-Regulation of Tim-3 in Monocytes and Macrophages in Plasmodium Infection and Its Association with Parasite Clearance. Front. Microbiol. 8, 1431. doi: 10.3389/ fmicb.2017.01431

Howes, R. E., Battle, K. E., Mendis, K. N., Smith, D. L., Cibulskis, R. E., Baird, J. K., et al. (2016). Global Epidemiology of Plasmodium vivax. Am. J. Trop. Med. Hyg. 95, 15-34. doi: 10.4269/ajtmh.16-0141

Huang, C. T., Workman, C. J., Flies, D., Pan, X., Marson, A. L., Zhou, G., et al. (2004). Role of LAG-3 in regulatory T cells. Immunity 21, 503-513. doi: 10.1016/j.immuni.2004.08.010

Huang, J., Liu, T., Xu, L. G., Chen, D., Zhai, Z., and Shu, H. B. (2005). SIKE is an IKK epsilon/TBK1-associated suppressor of TLR3- and virus-triggered IRF-3 activation pathways. EMBO J. 24, 4018-4028. doi: 10.1038/sj.emboj.7600863

Huang, H., Lamikanra, A. A., Alkaitis, M. S., Thezenas, M. L., Ramaprasad, A., Moussa, E., et al. (2014). Interleukin-10 regulates hepcidin in Plasmodium falciparum malaria. PloS One 9, e88408. doi: 10.1371/journal.pone.0088408

Hunt, N. H., Grau, G. E., Engwerda, C., Barnum, S. R., Van Der Heyde, H., Hansen, D. S., et al. (2010). Murine cerebral malaria: the whole story. Trends Parasitol. 26, 272-274. doi: 10.1016/j.pt.2010.03.006

Imkeller, K., Scally, S. W., Bosch, A., Marti, G. P., Costa, G., Triller, G., et al. (2018). Antihomotypic affinity maturation improves human B cell responses against a repetitive epitope. Science 360, 1358-1362. doi: 10.1126/ science.aar 5304

Inoue, S., Niikura, M., Takeo, S., Mineo, S., Kawakami, Y., Uchida, A., et al. (2012). Enhancement of dendritic cell activation via CD40 ligand-expressing gammadelta $\mathrm{T}$ cells is responsible for protective immunity to Plasmodium parasites. Proc. Natl. Acad. Sci. U.S.A. 109, 12129-12134. doi: 10.1073/ pnas. 1204480109

Ishido, S., Goto, E., Matsuki, Y., and Ohmura-Hoshino, M. (2009). E3 ubiquitin ligases for MHC molecules. Curr. Opin. Immunol. 21, 78-83. doi: 10.1016/ j.coi.2009.01.002

Ishizuka, A. S., Lyke, K. E., Dezure, A., Berry, A. A., Richie, T. L., Mendoza, F. H., et al. (2016). Protection against malaria at 1 year and immune correlates following PfSPZ vaccination. Nat. Med. 22, 614-623. doi: 10.1038/nm.4110

Issa, F., Robb, R. J., and Wood, K. J. (2013). The where and when of T cell regulation in transplantation. Trends Immunol. 34, 107-113. doi: 10.1016/ j.it.2012.11.003

Jangpatarapongsa, K., Chootong, P., Sattabongkot, J., Chotivanich, K., Sirichaisinthop, J., Tungpradabkul, S., et al. (2008). Plasmodium vivax parasites alter the balance of myeloid and plasmacytoid dendritic cells and the induction of regulatory T cells. Eur. J. Immunol. 38, 2697-2705. doi: 10.1002/eji.200838186

Jaramillo, M., Gowda, D. C., Radzioch, D., and Olivier, M. (2003). Hemozoin increases IFN-gamma-inducible macrophage nitric oxide generation through extracellular signal-regulated kinase- and NF-kappa B-dependent pathways. J. Immunol. 171, 4243-4253. doi: 10.4049/jimmunol.171.8.4243

Johnston, R. J., Comps-Agrar, L., Hackney, J., Yu, X., Huseni, M., Yang, Y., et al. (2014). The immunoreceptor TIGIT regulates antitumor and antiviral CD8(+) T cell effector function. Cancer Cell 26, 923-937. doi: 10.1016/j.ccell.2014.10.018
Ju, Y., Hou, N., Meng, J., Wang, X., Zhang, X., Zhao, D., et al. (2010). T cell immunoglobulin- and mucin-domain-containing molecule-3 (Tim-3) mediates natural killer cell suppression in chronic hepatitis B. J. Hepatol. 52, 322-329. doi: 10.1016/j.jhep.2009.12.005

Kadziolka, B., Lesniak, W., and Filipek, A. (2017). Regulation of CacyBP/SIP expression by NFAT1 transcription factor. Immunobiology 222, 872-877. doi: 10.1016/j.imbio.2017.05.002

Kalantari, P., Deoliveira, R. B., Chan, J., Corbett, Y., Rathinam, V., Stutz, A., et al. (2014). Dual engagement of the NLRP3 and AIM2 inflammasomes by plasmodium-derived hemozoin and DNA during malaria. Cell Rep. 6, 196210. doi: 10.1016/j.celrep.2013.12.014

Kanda, Y., Kawamura, H., Matsumoto, H., Kobayashi, T., Kawamura, T., and Abo, T. (2010). Identification and characterization of autoantibody-producing B220(low) B (B-1) cells appearing in malarial infection. Cell Immunol. 263, 49-54. doi: 10.1016/j.cellimm.2010.02.015

Kapelski, S., Klockenbring, T., Fischer, R., Barth, S., and Fendel, R. (2014). Assessment of the neutrophilic antibody-dependent respiratory burst (ADRB) response to Plasmodium falciparum. J. Leukoc. Biol. 96, 1131-1142. doi: 10.1189/jlb.4A0614-283RR

Karunarathne, D. S., Horne-Debets, J. M., Huang, J. X., Faleiro, R., Leow, C. Y., Amante, F., et al. (2016). Programmed Death-1 Ligand 2-Mediated Regulation of the PD-L1 to PD-1 Axis Is Essential for Establishing CD4(+) T Cell Immunity. Immunity 45, 333-345. doi: 10.1016/j.immuni.2016.07.017

Kent, L. N., Rumi, M. A., Kubota, K., Lee, D. S., and Soares, M. J. (2011). FOSL1 is integral to establishing the maternal-fetal interface. Mol. Cell Biol. 31, 48014813. doi: 10.1128/MCB.05780-11

Kimura, D., Miyakoda, M., Kimura, K., Honma, K., Hara, H., Yoshida, H., et al. (2016). Interleukin-27-Producing CD4(+) T Cells Regulate Protective Immunity during Malaria Parasite Infection. Immunity 44, 672-682. doi: 10.1016/j.immuni.2016.02.011

Kinjyo, I., Hanada, T., Inagaki-Ohara, K., Mori, H., Aki, D., Ohishi, M., et al. (2002). SOCS1/JAB is a negative regulator of LPS-induced macrophage activation. Immunity 17, 583-591. doi: 10.1016/S1074-7613(02)00446-6

Kordes, M., Matuschewski, K., and Hafalla, J. C. (2011). Caspase-1 activation of interleukin-1beta (IL-1beta) and IL-18 is dispensable for induction of experimental cerebral malaria. Infect. Immun. 79, 3633-3641. doi: 10.1128/ IAI.05459-11

Krishnegowda, G., Hajjar, A. M., Zhu, J., Douglass, E. J., Uematsu, S., Akira, S., et al. (2005). Induction of proinflammatory responses in macrophages by the glycosylphosphatidylinositols of Plasmodium falciparum: cell signaling receptors, glycosylphosphatidylinositol (GPI) structural requirement, and regulation of GPI activity. J. Biol. Chem. 280, 8606-8616. doi: 10.1074/ jbc.M413541200

Kumar, S., and Miller, L. H. (1990). Cellular mechanisms in immunity to blood stage infection. Immunol. Lett. 25, 109-114. doi: 10.1016/0165-2478(90)90100-5

Kumaratilake, L. M., and Ferrante, A. (2000). Opsonization and phagocytosis of Plasmodium falciparum merozoites measured by flow cytometry. Clin. Diagn Lab. Immunol. 7, 9-13. doi: 10.1128/CDLI.7.1.9-13.2000

Kurtovic, L., Boyle, M. J., Opi, D. H., Kennedy, A. T., Tham, W. H., Reiling, L., et al. (2020). Complement in malaria immunity and vaccines. Immunol. Rev. 293, 38-56. doi: 10.1111/imr.12802

Kurup, S. P., Obeng-Adjei, N., Anthony, S. M., Traore, B., Doumbo, O. K., Butler, N. S., et al. (2017). Regulatory T cells impede acute and long-term immunity to blood-stage malaria through CTLA-4. Nat. Med. 23, 1220-1225. doi: 10.1038/ nm. 4395

Langhorne, J., Gillard, S., Simon, B., Slade, S., and Eichmann, K. (1989). Frequencies of $\mathrm{CD} 4+\mathrm{T}$ cells reactive with Plasmodium chabaudi chabaudi: distinct response kinetics for cells with Th1 and Th2 characteristics during infection. Int. Immunol. 1, 416-424. doi: 10.1093/intimm/1.4.416

Latchman, Y., Wood, C. R., Chernova, T., Chaudhary, D., Borde, M., Chernova, I., et al. (2001). PD-L2 is a second ligand for PD-1 and inhibits T cell activation. Nat. Immunol. 2, 261-268. doi: 10.1038/85330

Le Bouteiller, P., Barakonyi, A., Giustiniani, J., Lenfant, F., Marie-Cardine, A., Aguerre-Girr, M., et al. (2002). Engagement of CD160 receptor by HLA-C is a triggering mechanism used by circulating natural killer (NK) cells to mediate cytotoxicity. Proc. Natl. Acad. Sci. U.S.A. 99, 16963-16968. doi: 10.1073/ pnas.012681099 
Lennartz, F., Adams, Y., Bengtsson, A., Olsen, R. W., Turner, L., Ndam, N. T., et al. (2017). Structure-Guided Identification of a Family of Dual Receptor-Binding PfEMP1 that Is Associated with Cerebral Malaria. Cell Host. Microbe 21, 403414. doi: 10.1016/j.chom.2017.02.009

Lennartz, F., Smith, C., Craig, A. G., and Higgins, M. K. (2019). Structural insights into diverse modes of ICAM-1 binding by Plasmodium falciparum-infected erythrocytes. Proc. Natl. Acad. Sci. U.S.A. 116, 20124-20134. doi: 10.1073/ pnas. 1911900116

Liehl, P., Zuzarte-Luis, V., Chan, J., Zillinger, T., Baptista, F., Carapau, D., et al. (2014). Host-cell sensors for Plasmodium activate innate immunity against liver-stage infection. Nat. Med. 20, 47-53. doi: 10.1038/nm.3424

Lin, Y., Wei, J., Fan, L., and Cheng, D. (2015). BTNL2 gene polymorphism and sarcoidosis susceptibility: a meta-analysis. PloS One 10, e0122639. doi: 10.1371/ journal.pone.0122639

Liu, D., Sheng, C., Gao, S., Yao, C., Li, J., Jiang, W., et al. (2015). SOCS3 Drives Proteasomal Degradation of TBK1 and Negatively Regulates Antiviral Innate Immunity. Mol. Cell Biol. 35, 2400-2413. doi: 10.1128/MCB.00090-15

Liu, T., Cheng, X., Ding, Y., Zhu, F., Fu, Y., Peng, X., et al. (2018). PD-1 deficiency promotes TFH cells expansion in ITV-immunized mice by upregulating cytokines secretion. Parasit. Vectors 11, 397. doi: 10.1186/s13071-018-2984-4

Liu, T., Lu, X., Zhao, C., Fu, X., Zhao, T., and Xu, W. (2015). PD-1 deficiency enhances humoral immunity of malaria infection treatment vaccine. Infect. Immun. 83, 2011-2017. doi: 10.1128/IAI.02621-14

Ma, C. S., Deenick, E. K., Batten, M., and Tangye, S. G. (2012). The origins, function, and regulation of T follicular helper cells. J. Exp. Med. 209, 12411253. doi: $10.1084 /$ jem.20120994

Macchia, G., Trombetta, D., Moller, E., Mertens, F., Storlazzi, C. T., DebiecRychter, M., et al. (2012). FOSL1 as a candidate target gene for 11q12 rearrangements in desmoplastic fibroblastoma. Lab. Invest. 92, 735-743. doi: 10.1038/labinvest.2012.46

Machado, F. S., Johndrow, J. E., Esper, L., Dias, A., Bafica, A., Serhan, C. N., et al. (2006). Anti-inflammatory actions of lipoxin A4 and aspirin-triggered lipoxin are SOCS-2 dependent. Nat. Med. 12, 330-334. doi: 10.1038/nm1355

Macian, F. (2005). NFAT proteins: key regulators of T-cell development and function. Nat. Rev. Immunol. 5, 472-484. doi: 10.1038/nri1632

Macri, C., Pang, E. S., Patton, T., and O'keeffe, M. (2018). Dendritic cell subsets. Semin. Cell Dev. Biol. 84, 11-21. doi: 10.1016/j.semcdb.2017.12.009

Maeda, M., Carpenito, C., Russell, R. C., Dasanjh, J., Veinotte, L. L., Ohta, H., et al. (2005). Murine CD160, Ig-like receptor on NK cells and NKT cells, recognizes classical and nonclassical MHC class I and regulates NK cell activation. J. Immunol. 175, 4426-4432. doi: 10.4049/jimmunol.175.7.4426

Manfredi, A. A., Ramirez, G. A., Rovere-Querini, P., and Maugeri, N. (2018). The Neutrophil's Choice: Phagocytose vs Make Neutrophil Extracellular Traps. Front. Immunol. 9, 288. doi: 10.3389/fimmu.2018.00288

Mantel, P. Y., and Marti, M. (2014). The role of extracellular vesicles in Plasmodium and other protozoan parasites. Cell Microbiol. 16, 344-354. doi: $10.1111 / \mathrm{cmi} .12259$

Marsh, K., Otoo, L., Hayes, R. J., Carson, D. C., and Greenwood, B. M. (1989). Antibodies to blood stage antigens of Plasmodium falciparum in rural Gambians and their relation to protection against infection. Trans. $R$ Soc. Trop. Med. Hyg. 83, 293-303. doi: 10.1016/0035-9203(89)90478-1

Martins, G. A., Tadokoro, C. E., Silva, R. B., Silva, J. S., and Rizzo, L. V. (2004). CTLA-4 blockage increases resistance to infection with the intracellular protozoan Trypanosoma cruzi. J. Immunol. 172, 4893-4901. doi: 10.4049/ jimmunol.172.8.4893

Marvel, J., and Mayer, A. (1988). CD45R gives immunofluorescence and transduces signals on mouse T cells. Eur. J. Immunol. 18, 825-828. doi: 10.1002/eji. 1830180526

Mchugh, R. S., Whitters, M. J., Piccirillo, C. A., Young, D. A., Shevach, E. M., Collins, M., et al. (2002). CD4(+)CD25(+) immunoregulatory T cells: gene expression analysis reveals a functional role for the glucocorticoid-induced TNF receptor. Immunity 16, 311-323. doi: 10.1016/S1074-7613(02)00280-7

Mcleod, B., Miura, K., Scally, S. W., Bosch, A., Nguyen, N., Shin, H., et al. (2019). Potent antibody lineage against malaria transmission elicited by human vaccination with Pfs25. Nat. Commun. 10, 4328. doi: 10.1038/s41467-019-11980-6

Mcnab, F., Mayer-Barber, K., Sher, A., Wack, A., and O'garra, A. (2015). Type I interferons in infectious disease. Nat. Rev. Immunol. 15, 87-103. doi: 10.1038/ nri3787
Medana, I. M., Hien, T. T., Day, N. P., Phu, N. H., Mai, N. T., Chu’ong, L. V., et al. (2002). The clinical significance of cerebrospinal fluid levels of kynurenine pathway metabolites and lactate in severe malaria. J. Infect. Dis. 185, 650-656. doi: $10.1086 / 339009$

Medana, I. M., Day, N. P., Salahifar-Sabet, H., Stocker, R., Smythe, G., Bwanaisa, L., et al. (2003). Metabolites of the kynurenine pathway of tryptophan metabolism in the cerebrospinal fluid of Malawian children with malaria. J. Infect. Dis. 188, 844-849. doi: 10.1086/377583

Mellor, A. L., and Munn, D. H. (2004). IDO expression by dendritic cells: tolerance and tryptophan catabolism. Nat. Rev. Immunol. 4, 762-774. doi: 10.1038/ nri1457

Mendis, K. N., and Targett, G. A. (1979). Immunisation against gametes and asexual erythrocytic stages of a rodent malaria parasite. Nature 277, 389-391. doi: $10.1038 / 277389 \mathrm{a} 0$

Mendonca, V. R., and Barral-Netto, M. (2015). Immunoregulation in human malaria: the challenge of understanding asymptomatic infection. Mem. Inst. Oswaldo Cruz 110, 945-955. doi: 10.1590/0074-02760150241

Miller, J. L., Sack, B. K., Baldwin, M., Vaughan, A. M., and Kappe, S. H. I. (2014). Interferon-mediated innate immune responses against malaria parasite liver stages. Cell Rep. 7, 436-447. doi: 10.1016/j.celrep.2014.03.018

Mitchell, A. J., Hansen, A. M., Hee, L., Ball, H. J., Potter, S. M., Walker, J. C., et al. (2005). Early cytokine production is associated with protection from murine cerebral malaria. Infect. Immun. 73, 5645-5653. doi: 10.1128/IAI.73.9.56455653.2005

Mittal, S. K., Cho, K. J., Ishido, S., and Roche, P. A. (2015). Interleukin 10 (IL-10)mediated Immunosuppression: MARCH-I INDUCTION REGULATES ANTIGEN PRESENTATION BY MACROPHAGES BUT NOT DENDRITIC CELLS. J. Biol. Chem. 290, 27158-27167. doi: 10.1074/jbc.M115.682708

Miyakoda, M., Kimura, D., Honma, K., Kimura, K., Yuda, M., and Yui, K. (2012). Development of memory CD8+ T cells and their recall responses during bloodstage infection with Plasmodium berghei ANKA. J. Immunol. 189, 4396-4404. doi: 10.4049/jimmunol.1200781

Montes De Oca, M., Kumar, R., Rivera, F. L., Amante, F. H., Sheel, M., Faleiro, R. J., et al. (2016). Type I Interferons Regulate Immune Responses in Humans with Blood-Stage Plasmodium falciparum Infection. Cell Rep. 17, 399-412. doi: 10.1016/j.celrep.2016.09.015

Mordmuller, B., Surat, G., Lagler, H., Chakravarty, S., Ishizuka, A. S., Lalremruata, A., et al. (2017). Sterile protection against human malaria by chemoattenuated PfSPZ vaccine. Nature 542, 445-449. doi: 10.1038/nature21060

Moretto, M. M., Hwang, S., and Khan, I. A. (2017). Downregulated IL-21 Response and T Follicular Helper Cell Exhaustion Correlate with Compromised CD8 T Cell Immunity during Chronic Toxoplasmosis. Front. Immunol. 8, 1436. doi: 10.3389/fimmu.2017.01436

Moschonas, A., Ioannou, M., and Eliopoulos, A. G. (2012). CD40 stimulates a "feed-forward" NF-kappaB-driven molecular pathway that regulates IFN-beta expression in carcinoma cells. J. Immunol. 188, 5521-5527. doi: 10.4049/ jimmunol.1200133

Mota, M. M., Pradel, G., Vanderberg, J. P., Hafalla, J. C., Frevert, U., Nussenzweig, R. S., et al. (2001). Migration of Plasmodium sporozoites through cells before infection. Science 291, 141-144. doi: 10.1126/science.291.5501.141

Murray, S. A., Mohar, I., Miller, J. L., Brempelis, K. J., Vaughan, A. M., Kappe, S. H., et al. (2015). CD40 is required for protective immunity against liver stage Plasmodium infection. J. Immunol. 194, 2268-2279. doi: 10.4049/ jimmunol.1401724

Murugan, R., Buchauer, L., Triller, G., Kreschel, C., Costa, G., Pidelaserra Marti, G., et al. (2018). Clonal selection drives protective memory B cell responses in controlled human malaria infection. Sci. Immunol. 3, eaap802. doi: 10.1126/ sciimmunol.aap8029

Muscate, F., Stetter, N., Schramm, C., Schulze Zur Wiesch, J., Bosurgi, L., and Jacobs, T. (2018). HVEM and CD160: Regulators of Immunopathology During Malaria Blood-Stage. Front. Immunol. 9, 2611. doi: 10.3389/fimmu.2018.02611

Nair, S. C., Xu, R., Pattaradilokrat, S., Wu, J., Qi, Y., Zilversmit, M., et al. (2017). A Plasmodium yoelii HECT-like E3 ubiquitin ligase regulates parasite growth and virulence. Nat. Commun. 8, 223. doi: 10.1038/s41467-017-00267-3

Nair, S. R., Abraham, R., Sundaram, S., and Sreekumar, E. (2017). Interferon regulated gene (IRG) expression-signature in a mouse model of chikungunya virus neurovirulence. J. Neurovirol. 23, 886-902. doi: 10.1007/s13365-0170583-3 
Naka, T., Narazaki, M., Hirata, M., Matsumoto, T., Minamoto, S., Aono, A., et al. (1997). Structure and function of a new STAT-induced STAT inhibitor. Nature 387, 924-929. doi: 10.1038/43219

Naka, T., Matsumoto, T., Narazaki, M., Fujimoto, M., Morita, Y., Ohsawa, Y., et al. (1998). Accelerated apoptosis of lymphocytes by augmented induction of Bax in SSI-1 (STAT-induced STAT inhibitor-1) deficient mice. Proc. Natl. Acad. Sci. U.S.A. 95, 15577-15582. doi: 10.1073/pnas.95.26.15577

Nakae, S., Suto, H., Iikura, M., Kakurai, M., Sedgwick, J. D., Tsai, M., et al. (2006). Mast cells enhance $\mathrm{T}$ cell activation: importance of mast cell costimulatory molecules and secreted TNF. J. Immunol. 176, 2238-2248. doi: 10.4049/ jimmunol.176.4.2238

Nakagawa, R., Naka, T., Tsutsui, H., Fujimoto, M., Kimura, A., Abe, T., et al. (2002). SOCS-1 participates in negative regulation of LPS responses. Immunity 17, 677-687. doi: 10.1016/S1074-7613(02)00449-1

Ndungu, F. M., Olotu, A., Mwacharo, J., Nyonda, M., Apfeld, J., Mramba, L. K., et al. (2012). Memory B cells are a more reliable archive for historical antimalarial responses than plasma antibodies in no-longer exposed children. Proc. Natl. Acad. Sci. U.S.A. 109, 8247-8252. doi: 10.1073/pnas.1200472109

Ndungu, F. M., Lundblom, K., Rono, J., Illingworth, J., Eriksson, S., and Farnert, A. (2013). Long-lived Plasmodium falciparum specific memory B cells in naturally exposed Swedish travelers. Eur. J. Immunol. 43, 2919-2929. doi: 10.1002/eji.201343630

Niikura, M., Kamiya, S., Kita, K., and Kobayashi, F. (2008). Coinfection with nonlethal murine malaria parasites suppresses pathogenesis caused by Plasmodium berghei NK65. J. Immunol. 180, 6877-6884. doi: 10.4049/ jimmunol.180.10.6877

Niknam, A., Karimi, M. H., Geramizadeh, B., Roozbeh, J., Yaghobi, R., and Salehipour, M. (2017). Polymorphisms of the Costimulatory Genes CTLA-4, CD28, PD-1, and ICOS and Outcome of Kidney Transplants in Iranian Patients. Exp. Clin. Transplant. 15, 295-305. doi: 10.6002/ect.2014.0253

Nishioka, T., Nishida, E., Iida, R., Morita, A., and Shimizu, J. (2008). In vivo expansion of CD4+Foxp3+ regulatory $\mathrm{T}$ cells mediated by GITR molecules. Immunol. Lett. 121, 97-104. doi: 10.1016/j.imlet.2008.09.003

Nocentini, G., Ronchetti, S., Cuzzocrea, S., and Riccardi, C. (2007). GITR/GITRL: more than an effector T cell co-stimulatory system. Eur. J. Immunol. 37, 11651169. doi: 10.1002/eji.200636933

Obeng-Adjei, N., Portugal, S., Tran, T. M., Yazew, T. B., Skinner, J., Li, S., et al. (2015). Circulating Th1-Cell-type Tfh Cells that Exhibit Impaired B Cell Help Are Preferentially Activated during Acute Malaria in Children. Cell Rep. 13, 425-439. doi: 10.1016/j.celrep.2015.09.004

Ohmura-Hoshino, M., Goto, E., Matsuki, Y., Aoki, M., Mito, M., Uematsu, M., et al. (2006). A novel family of membrane-bound E3 ubiquitin ligases. J. Biochem. 140, 147-154. doi: 10.1093/jb/mvj160

Okazaki, T., and Honjo, T. (2006). The PD-1-PD-L pathway in immunological tolerance. Trends Immunol. 27, 195-201. doi: 10.1016/j.it.2006.02.001

O'neill, L. A., Golenbock, D., and Bowie, A. G. (2013). The history of Toll-like receptors - redefining innate immunity. Nat. Rev. Immunol. 13, 453-460. doi: 10.1038/nri3446

Orsini, G., Legitimo, A., Failli, A., Massei, F., Biver, P., and Consolini, R. (2012). Enumeration of human peripheral blood dendritic cells throughout the life. Int. Immunol. 24, 347-356. doi: 10.1093/intimm/dxs006

Ortonne, N., Ram-Wolff, C., Giustiniani, J., Marie-Cardine, A., Bagot, M., Mecheri, S., et al. (2011). Human and mouse mast cells express and secrete the GPI-anchored isoform of CD160. J. Invest. Dermatol. 131, 916-924. doi: 10.1038/jid.2010.412

Osier, F. H., Fegan, G., Polley, S. D., Murungi, L., Verra, F., Tetteh, K. K., et al. (2008). Breadth and magnitude of antibody responses to multiple Plasmodium falciparum merozoite antigens are associated with protection from clinical malaria. Infect. Immun. 76, 2240-2248. doi: 10.1128/IAI.01585-07

Othman, A. S., Franke-Fayard, B. M., Imai, T., Van Der Gracht, E. T. I., Redeker, A., Salman, A. M., et al. (2018). OX40 Stimulation Enhances Protective Immune Responses Induced After Vaccination With Attenuated Malaria Parasites. Front. Cell Infect. Microbiol. 8, 247. doi: 10.3389/fcimb.2018.00247

Otterdal, K., Berg, A., Michelsen, A. E., Patel, S., Tellevik, M. G., Haanshuus, C. G., et al. (2018). Soluble markers of neutrophil, T-cell and monocyte activation are associated with disease severity and parasitemia in falciparum malaria. BMC Infect. Dis. 18, 670. doi: 10.1186/s12879-018-3593-8
Ouattara, A., and Laurens, M. B. (2015). Vaccines against malaria. Clin. Infect. Dis. 60, 930-936. doi: 10.1093/cid/ciu954

Pan, Y., Sun, X., Li, D., Zhao, Y., Jin, F., and Cao, Y. (2020). PD-1 blockade promotes immune memory following Plasmodium berghei ANKA reinfection. Int. Immunopharmacol. 80, 106186. doi: 10.1016/j.intimp.2020.106186

Parmar, R., Patel, H., Yadav, N., Parikh, R., Patel, K., Mohankrishnan, A., et al. (2018). Infectious Sporozoites of Plasmodium berghei Effectively Activate Liver CD8alpha(+) Dendritic Cells. Front. Immunol. 9, 192. doi: 10.3389/ fimmu.2018.00192

Parroche, P., Lauw, F. N., Goutagny, N., Latz, E., Monks, B. G., Visintin, A., et al. (2007). Malaria hemozoin is immunologically inert but radically enhances innate responses by presenting malaria DNA to Toll-like receptor 9. Proc. Natl. Acad. Sci. U.S.A. 104, 1919-1924. doi: 10.1073/pnas.0608745104

Perez-Mazliah, D., and Langhorne, J. (2014). CD4 T-cell subsets in malaria: TH1/ TH2 revisited. Front. Immunol. 5, 671. doi: 10.3389/fimmu.2014.00671

Perez-Mazliah, D., Ng, D. H., Freitas Do Rosario, A. P., Mclaughlin, S., MastelicGavillet, B., Sodenkamp, J., et al. (2015). Disruption of IL-21 signaling affects T cell-B cell interactions and abrogates protective humoral immunity to malaria. PloS Pathog. 11, e1004715. doi: 10.1371/journal.ppat.1004715

Perez-Mazliah, D., Nguyen, M. P., Hosking, C., Mclaughlin, S., Lewis, M. D., Tumwine, I., et al. (2017). Follicular Helper T Cells are Essential for the Elimination of Plasmodium Infection. EBioMedicine 24, 216-230. doi: 10.1016/ j.ebiom.2017.08.030

Peters, N. C., Egen, J. G., Secundino, N., Debrabant, A., Kimblin, N., Kamhawi, S., et al. (2008). In vivo imaging reveals an essential role for neutrophils in leishmaniasis transmitted by sand flies. Science 321, 970-974. doi: 10.1126/ science. 1159194

Ratelade, J., and Verkman, A. S. (2014). Inhibitor(s) of the classical complement pathway in mouse serum limit the utility of mice as experimental models of neuromyelitis optica. Mol. Immunol. 62, 104-113. doi: 10.1016/ j.molimm.2014.06.003

Renaud, S. J., Kubota, K., Rumi, M. A., and Soares, M. J. (2014). The FOS transcription factor family differentially controls trophoblast migration and invasion. J. Biol. Chem. 289, 5025-5039. doi: 10.1074/jbc.M113.523746

Renno, T., Attinger, A., Rimoldi, D., Hahne, M., Tschopp, J., and Macdonald, H. R. (1998). Expression of B220 on activated T cell blasts precedes apoptosis. Eur. J. Immunol. 28, 540-547. doi: 10.1002/(SICI)1521-4141(199802)28:02<540:: AID-IMMU540>3.0.CO;2-Y

Ribot, J. C., Debarros, A., Mancio-Silva, L., Pamplona, A., and Silva-Santos, B. (2012). B7-CD28 costimulatory signals control the survival and proliferation of murine and human gammadelta T cells via IL-2 production. J. Immunol. 189, 1202-1208. doi: 10.4049/jimmunol.1200268

Ridge, J. P., Di Rosa, F., and Matzinger, P. (1998). A conditioned dendritic cell can be a temporal bridge between a CD4+ T-helper and a T-killer cell. Nature 393, 474-478. doi: 10.1038/30989

Riley, E. M., and Stewart, V. A. (2013). Immune mechanisms in malaria: new insights in vaccine development. Nat. Med. 19, 168-178. doi: 10.1038/nm.3083

Rivera-Correa, J., Guthmiller, J. J., Vijay, R., Fernandez-Arias, C., Pardo-Ruge, M. A., Gonzalez, S., et al. (2017). Plasmodium DNA-mediated TLR9 activation of T-bet (+) B cells contributes to autoimmune anaemia during malaria. Nat. Commun. 8, 1282. doi: 10.1038/s41467-017-01476-6

Rodig, N., Ryan, T., Allen, J. A., Pang, H., Grabie, N., Chernova, T., et al. (2003). Endothelial expression of PD-L1 and PD-L2 down-regulates CD8+ T cell activation and cytolysis. Eur. J. Immunol. 33, 3117-3126. doi: 10.1002/ eji. 200324270

Rodig, S. J., Shahsafaei, A., Li, B., and Dorfman, D. M. (2005). The CD45 isoform B220 identifies select subsets of human B cells and B-cell lymphoproliferative disorders. Hum. Pathol. 36, 51-57. doi: 10.1016/j.humpath.2004.10.016

Roestenberg, M., Mccall, M., Hopman, J., Wiersma, J., Luty, A. J., Van Gemert, G. J., et al. (2009). Protection against a malaria challenge by sporozoite inoculation. N Engl. J. Med. 361, 468-477. doi: 10.1056/NEJMoa0805832

Ross, R. (1896). Dr. Manson's Mosquito-Malaria Theory. Ind. Med. Gaz. 31, 264.

Rothbard, J. B., and Gefter, M. L. (1991). Interactions between immunogenic peptides and MHC proteins. Annu. Rev. Immunol. 9, 527-565. doi: 10.1146/ annurev.iy.09.040191.002523

Rowe, J. A., Claessens, A., Corrigan, R. A., and Arman, M. (2009). Adhesion of Plasmodium falciparum-infected erythrocytes to human cells: molecular 
mechanisms and therapeutic implications. Expert Rev. Mol. Med. 11, e16. doi: $10.1017 /$ S1462399409001082

Ryg-Cornejo, V., Ioannidis, L. J., Ly, A., Chiu, C. Y., Tellier, J., Hill, D. L., et al. (2016). Severe Malaria Infections Impair Germinal Center Responses by Inhibiting T Follicular Helper Cell Differentiation. Cell Rep. 14, 68-81. doi: 10.1016/j.celrep.2015.12.006

Sabatos, C. A., Chakravarti, S., Cha, E., Schubart, A., Sanchez-Fueyo, A., Zheng, X. X., et al. (2003). Interaction of Tim-3 and Tim-3 ligand regulates T helper type 1 responses and induction of peripheral tolerance. Nat. Immunol. 4, 1102-1110. doi: $10.1038 /$ ni988

Sabins, N. C., Chornoguz, O., Leander, K., Kaplan, F., Carter, R., Kinder, M., et al. (2017). TIM-3 Engagement Promotes Effector Memory T Cell Differentiation of Human Antigen-Specific CD8 T Cells by Activating mTORC1. J. Immunol. 199, 4091-4102. doi: 10.4049/jimmunol.1701030

Sakuishi, K., Jayaraman, P., Behar, S. M., Anderson, A. C., and Kuchroo, V. K. (2011). Emerging Tim-3 functions in antimicrobial and tumor immunity. Trends Immunol. 32, 345-349. doi: 10.1016/j.it.2011.05.003

Samji, T., Hong, S., and Means, R. E. (2014). The Membrane Associated RING-CH Proteins: A Family of E3 Ligases with Diverse Roles through the Cell. Int. Sch. Res. Notices 2014, 637295. doi: 10.1155/2014/637295

Sanchez-Torres, L., Rodriguez-Ropon, A., Aguilar-Medina, M., and FavilaCastillo, L. (2001). Mouse splenic CD4+ and CD8+ T cells undergo extensive apoptosis during a Plasmodium chabaudi chabaudi AS infection. Parasite Immunol. 23, 617-626. doi: 10.1046/j.1365-3024.2001.00422.x

Schoenberger, S. P., Toes, R. E., Van Der Voort, E. I., Offringa, R., and Melief, C. J. (1998). T-cell help for cytotoxic T lymphocytes is mediated by CD40-CD40L interactions. Nature 393, 480-483. doi: 10.1038/31002

Schofield, L., Ioannidis, L. J., Karl, S., Robinson, L. J., Tan, Q. Y., Poole, D. P., et al. (2017). Synergistic effect of IL-12 and IL-18 induces TIM3 regulation of gammadelta $\mathrm{T}$ cell function and decreases the risk of clinical malaria in children living in Papua New Guinea. BMC Med. 15, 114. doi: 10.1186/ s12916-017-0883-8

Schroder, K., and Tschopp, J. (2010). The inflammasomes. Cell 140, 821-832. doi: 10.1016/j.cell.2010.01.040

Sedegah, M., Sim, B. K., Mason, C., Nutman, T., Malik, A., Roberts, C., et al. (1992). Naturally acquired CD8+ cytotoxic T lymphocytes against the Plasmodium falciparum circumsporozoite protein. J. Immunol. 149, 966-971.

Seder, R. A., Chang, L. J., Enama, M. E., Zephir, K. L., Sarwar, U. N., Gordon, I. J., et al. (2013). Protection against malaria by intravenous immunization with a nonreplicating sporozoite vaccine. Science 341, 1359-1365. doi: 10.1126/ science. 1241800

Segal, A. W. (2005). How neutrophils kill microbes. Annu. Rev. Immunol. 23, $197-$ 223. doi: 10.1146/annurev.immunol.23.021704.115653

Sharma, S., Deoliveira, R. B., Kalantari, P., Parroche, P., Goutagny, N., Jiang, Z., et al. (2011). Innate immune recognition of an AT-rich stem-loop DNA motif in the Plasmodium falciparum genome. Immunity 35, 194-207. doi: 10.1016/ j.immuni.2011.05.016

Sharpe, A. H., and Freeman, G. J. (2002). The B7-CD28 superfamily. Nat. Rev. Immunol. 2, 116-126. doi: 10.1038/nri727

Shear, H. L., Srinivasan, R., Nolan, T., and Ng, C. (1989). Role of IFN-gamma in lethal and nonlethal malaria in susceptible and resistant murine hosts. J. Immunol. 143, 2038-2044.

Shevach, E. M., and Stephens, G. L. (2006). The GITR-GITRL interaction: costimulation or contrasuppression of regulatory activity? Nat. Rev. Immunol. 6, 613-618. doi: 10.1038/nri1867

Shimizu, J., Yamazaki, S., Takahashi, T., Ishida, Y., and Sakaguchi, S. (2002). Stimulation of $\mathrm{CD} 25(+) \mathrm{CD} 4(+)$ regulatory $\mathrm{T}$ cells through GITR breaks immunological self-tolerance. Nat. Immunol. 3, 135-142. doi: 10.1038/ni759

Shin, D. S., Jordan, A., Basu, S., Thomas, R. M., Bandyopadhyay, S., De Zoeten, E. F., et al. (2014). Regulatory T cells suppress CD4+ T cells through NFAT-dependent transcriptional mechanisms. EMBO Rep. 15, 991-999. doi: 10.15252/ embr.201338233

Shio, M. T., Eisenbarth, S. C., Savaria, M., Vinet, A. F., Bellemare, M. J., Harder, K. W., et al. (2009). Malarial hemozoin activates the NLRP3 inflammasome through Lyn and Syk kinases. PloS Pathog. 5, e1000559. doi: 10.1371/ journal.ppat.1000559

Sibilano, R., Gaudenzio, N., Degorter, M. K., Reber, L. L., Hernandez, J. D., Starkl, P. M., et al. (2016). A TNFRSF14-FcvarepsilonRI-mast cell pathway contributes to development of multiple features of asthma pathology in mice. Nat. Commun. 7, 13696. doi: 10.1038/ncomms13696

Silveira, E. L. V., Dominguez, M. R., and Soares, I. S. (2018). To B or Not to B: Understanding B Cell Responses in the Development of Malaria Infection. Front. Immunol. 9, 2961. doi: 10.3389/fimmu.2018.02961

Singh, B., and Daneshvar, C. (2013). Human infections and detection of Plasmodium knowlesi. Clin. Microbiol. Rev. 26, 165-184. doi: 10.1128/ CMR.00079-12

Soroosh, P., Doherty, T. A., So, T., Mehta, A. K., Khorram, N., Norris, P. S., et al. (2011). Herpesvirus entry mediator (TNFRSF14) regulates the persistence of T helper memory cell populations. J. Exp. Med. 208, 797-809. doi: 10.1084/ jem.20101562

Soto-Nieves, N., Puga, I., Abe, B. T., Bandyopadhyay, S., Baine, I., Rao, A., et al. (2009). Transcriptional complexes formed by NFAT dimers regulate the induction of T cell tolerance. J. Exp. Med. 206, 867-876. doi: 10.1084/ jem.20082731

Soulat, D., and Bogdan, C. (2017). Function of Macrophage and Parasite Phosphatases in Leishmaniasis. Front. Immunol. 8, 1838. doi: 10.3389/ fimmu.2017.01838

Sponaas, A. M., Freitas Do Rosario, A. P., Voisine, C., Mastelic, B., Thompson, J., Koernig, S., et al. (2009). Migrating monocytes recruited to the spleen play an important role in control of blood stage malaria. Blood 114, 5522-5531. doi: 10.1182/blood-2009-04-217489

Springer, A. L., Smith, L. M., Mackay, D. Q., Nelson, S. O., and Smith, J. D. (2004). Functional interdependence of the DBLbeta domain and $\mathrm{c} 2$ region for binding of the Plasmodium falciparum variant antigen to ICAM-1. Mol. Biochem. Parasitol. 137, 55-64. doi: 10.1016/j.molbiopara.2004.03.019

Starr, R., Willson, T. A., Viney, E. M., Murray, L. J., Rayner, J. R., Jenkins, B. J., et al. (1997). A family of cytokine-inducible inhibitors of signalling. Nature 387, 917-921. doi: 10.1038/43206

Starr, R., Metcalf, D., Elefanty, A. G., Brysha, M., Willson, T. A., Nicola, N. A., et al. (1998). Liver degeneration and lymphoid deficiencies in mice lacking suppressor of cytokine signaling-1. Proc. Natl. Acad. Sci. U.S.A. 95, 1439514399. doi: 10.1073/pnas.95.24.14395

Stegmann, K. A., De Souza, J. B., and Riley, E. M. (2015). IL-18-induced expression of high-affinity IL-2R on murine NK cells is essential for NK-cell IFN-gamma production during murine Plasmodium yoelii infection. Eur. J. Immunol. 45, 3431-3440. doi: 10.1002/eji.201546018

Steinberg, M. W., Huang, Y., Wang-Zhu, Y., Ware, C. F., Cheroutre, H., and Kronenberg, M. (2013). BTLA interaction with HVEM expressed on CD8(+) T cells promotes survival and memory generation in response to a bacterial infection. PloS One 8, e77992. doi: 10.1371/journal.pone.0077992

Stevenson, M. M., and Riley, E. M. (2004). Innate immunity to malaria. Nat. Rev. Immunol. 4, 169-180. doi: 10.1038/nri1311

Stevenson, M. M., Tam, M. F., Wolf, S. F., and Sher, A. (1995). IL-12-induced protection against blood-stage Plasmodium chabaudi AS requires IFN-gamma and TNF-alpha and occurs via a nitric oxide-dependent mechanism. J. Immunol. 155, 2545-2556.

Stirnweiss, A., Ksienzyk, A., Klages, K., Rand, U., Grashoff, M., Hauser, H., et al. (2010). IFN regulatory factor-1 bypasses IFN-mediated antiviral effects through viperin gene induction. J. Immunol. 184, 5179-5185. doi: 10.4049/ jimmunol.0902264

Stone, W. J. R., Campo, J. J., Ouedraogo, A. L., Meerstein-Kessel, L., Morlais, I., Da, D., et al. (2018). Unravelling the immune signature of Plasmodium falciparum transmission-reducing immunity. Nat. Commun. 9, 558. doi: 10.1038/s41467017-02646-2

Storti-Melo, L. M., Da Costa, D. R., Souza-Neiras, W. C., Cassiano, G. C., Couto, V. S., Povoa, M. M., et al. (2012). Influence of HLA-DRB-1 alleles on the production of antibody against CSP, MSP-1, AMA-1, and DBP in Brazilian individuals naturally infected with Plasmodium vivax. Acta Trop. 121, $152-$ 155. doi: 10.1016/j.actatropica.2011.10.009

Sturm, A., Amino, R., Van De Sand, C., Regen, T., Retzlaff, S., Rennenberg, A., et al. (2006). Manipulation of host hepatocytes by the malaria parasite for delivery into liver sinusoids. Science 313, 1287-1290. doi: 10.1126/ science. 1129720

Su, Z., and Stevenson, M. M. (2000). Central role of endogenous gamma interferon in protective immunity against blood-stage Plasmodium chabaudi AS infection. Infect. Immun. 68, 4399-4406. doi: 10.1128/IAI.68.8.4399-4406.2000 
Subramaniam, K. S., Spaulding, E., Ivan, E., Mutimura, E., Kim, R. S., Liu, X., et al. (2015). The T-Cell Inhibitory Molecule Butyrophilin-Like 2 Is Up-regulated in Mild Plasmodium falciparum Infection and Is Protective During Experimental Cerebral Malaria. J. Infect. Dis. 212, 1322-1331. doi: 10.1093/infdis/jiv217

Sun, Y., Brown, N. K., Ruddy, M. J., Miller, M. L., Lee, Y., Wang, Y., et al. (2009). B and $\mathrm{T}$ lymphocyte attenuator tempers early infection immunity. J. Immunol. 183, 1946-1951. doi: 10.4049/jimmunol.0801866

Surls, J., Nazarov-Stoica, C., Kehl, M., Casares, S., and Brumeanu, T. D. (2010). Differential effect of CD4+Foxp3+ T-regulatory cells on the B and T helper cell responses to influenza virus vaccination. Vaccine 28, 7319-7330. doi: 10.1016/ j.vaccine.2010.08.074

Swanson, R. M., Gavin, M. A., Escobar, S. S., Rottman, J. B., Lipsky, B. P., Dube, S., et al. (2013). Butyrophilin-like 2 modulates B7 costimulation to induce Foxp3 expression and regulatory $\mathrm{T}$ cell development in mature $\mathrm{T}$ cells. J. Immunol. 190, 2027-2035. doi: 10.4049/jimmunol.1201760

Takeuchi, O., and Akira, S. (2010). Pattern recognition receptors and inflammation. Cell 140, 805-820. doi: 10.1016/j.cell.2010.01.022

Tamura, T., Kimura, K., Yui, K., and Yoshida, S. (2015). Reduction of conventional dendritic cells during Plasmodium infection is dependent on activation induced cell death by type I and II interferons. Exp. Parasitol. 159, 127-135. doi: 10.1016/j.exppara.2015.09.010

Tavares, J., Formaglio, P., Thiberge, S., Mordelet, E., Van Rooijen, N., Medvinsky, A., et al. (2013). Role of host cell traversal by the malaria sporozoite during liver infection. J. Exp. Med. 210, 905-915. doi: 10.1084/jem.20121130

Taylor, M. W., and Feng, G. S. (1991). Relationship between interferon-gamma, indoleamine 2,3-dioxygenase, and tryptophan catabolism. FASEB J. 5, 25162522. doi: $10.1096 /$ fasebj.5.11.1907934

Thaiss, C. A., Levy, M., Itav, S., and Elinav, E. (2016). Integration of Innate Immune Signaling. Trends Immunol. 37, 84-101. doi: 10.1016/j.it.2015.12.003

Tian, X., Lin, Y., Cui, C., Su, M., and Lai, L. (2019). BTNL2-Ig Protein Attenuates Type 1 Diabetes in Non-Obese Diabetic (NOD) Mice. Adv. Healthc. Mater. 8, e1800987. doi: 10.1002/adhm.201800987

Torcia, M. G., Santarlasci, V., Cosmi, L., Clemente, A., Maggi, L., Mangano, V. D., et al. (2008). Functional deficit of T regulatory cells in Fulani, an ethnic group with low susceptibility to Plasmodium falciparum malaria. Proc. Natl. Acad. Sci. U.S.A. 105, 646-651. doi: 10.1073/pnas.0709969105

Torgler, R., Bongfen, S. E., Romero, J. C., Tardivel, A., Thome, M., and Corradin, G. (2008). Sporozoite-mediated hepatocyte wounding limits Plasmodium parasite development via MyD88-mediated NF-kappa B activation and inducible NO synthase expression. J. Immunol. 180, 3990-3999. doi: 10.4049/jimmunol. 180.6 .3990

Tweedell, R., Tao, D., and Dinglasan, R. R. (2015). The cellular and proteomic response of primary and immortalized murine Kupffer cells following immune stimulation diverges from that of monocyte-derived macrophages. Proteomics 15, 545-553. doi: 10.1002/pmic.201400216

Tweedell, R. E., Qi, L., Sun, Z., and Dinglasan, R. R. (2018). Kupffer Cells Survive Plasmodium berghei Sporozoite Exposure and Respond with a Rapid Cytokine Release. Pathogens 7, 91. doi: 10.3390/pathogens7040091

Ubillos, I., Campo, J. J., Requena, P., Ome-Kaius, M., Hanieh, S., Rose, H., et al. (2017). Chronic Exposure to Malaria Is Associated with Inhibitory and Activation Markers on Atypical Memory B Cells and Marginal Zone-Like B Cells. Front. Immunol. 8, 966. doi: 10.3389/fimmu.2017.00966

Van Kooten, C., and Banchereau, J. (2000). CD40-CD40 ligand. J. Leukoc. Biol. 67, 2-17. doi: $10.1002 / j \mathrm{lb} .67 .1 .2$

Vendel, A. C., Calemine-Fenaux, J., Izrael-Tomasevic, A., Chauhan, V., Arnott, D., and Eaton, D. L. (2009). B and T lymphocyte attenuator regulates B cell receptor signaling by targeting Syk and BLNK. J. Immunol. 182, 1509-1517. doi: 10.4049/jimmunol.182.3.1509

Vijay, R., Guthmiller, J. J., Sturtz, A. J., Surette, F. A., Rogers, K. J., Sompallae, R. R., et al. (2020). Infection-induced plasmablasts are a nutrient sink that impairs humoral immunity to malaria. Nat. Immunol. 21, 790-801. doi: 10.1038/ s41590-020-0678-5

Villegas-Mendez, A., Inkson, C. A., Shaw, T. N., Strangward, P., and Couper, K. N. (2016). Long-Lived CD4+IFN-gamma+ T Cells rather than Short-Lived CD4 +IFN-gamma+IL-10+ T Cells Initiate Rapid IL-10 Production To Suppress Anamnestic T Cell Responses during Secondary Malaria Infection. J. Immunol. 197, 3152-3164. doi: 10.4049/jimmunol.1600968
Vinetz, J. M., Kumar, S., Good, M. F., Fowlkes, B. J., Berzofsky, J. A., and Miller, L. H. (1990). Adoptive transfer of CD8+ T cells from immune animals does not transfer immunity to blood stage Plasmodium yoelii malaria. J. Immunol. 144, 1069-1074.

Vinuesa, C. G., and Cyster, J. G. (2011). How T cells earn the follicular rite of passage. Immunity 35, 671-680. doi: 10.1016/j.immuni.2011.11.001

Wahlgren, M., Goel, S., and Akhouri, R. R. (2017). Variant surface antigens of Plasmodium falciparum and their roles in severe malaria. Nat. Rev. Microbiol. 15, 479-491. doi: 10.1038/nrmicro.2017.47

Walker, J. A., and Mckenzie, A. N. J. (2018). TH2 cell development and function. Nat. Rev. Immunol. 18, 121-133. doi: 10.1038/nri.2017.118

Walker, L. S., Gulbranson-Judge, A., Flynn, S., Brocker, T., Raykundalia, C., Goodall, M., et al. (1999). Compromised OX40 function in CD28-deficient mice is linked with failure to develop CXC chemokine receptor 5-positive CD4 cells and germinal centers. J. Exp. Med. 190, 1115-1122. doi: 10.1084/ jem.190.8.1115

Walther, M., Woodruff, J., Edele, F., Jeffries, D., Tongren, J. E., King, E., et al. (2006). Innate immune responses to human malaria: heterogeneous cytokine responses to blood-stage Plasmodium falciparum correlate with parasitological and clinical outcomes. J. Immunol. 177, 5736-5745. doi: 10.4049/ jimmunol.177.8.5736

Wei, L., Laurence, A., Elias, K. M., and O'shea, J. J. (2007). IL-21 is produced by Th17 cells and drives IL-17 production in a STAT3-dependent manner. J. Biol. Chem. 282, 34605-34610. doi: 10.1074/jbc.M705100200

Weiss, G. E., Crompton, P. D., Li, S., Walsh, L. A., Moir, S., Traore, B., et al. (2009). Atypical memory B cells are greatly expanded in individuals living in a malariaendemic area. J. Immunol. 183, 2176-2182. doi: 10.4049/jimmunol.0901297

Weiss, G. E., Traore, B., Kayentao, K., Ongoiba, A., Doumbo, S., Doumtabe, D., et al. (2010). The Plasmodium falciparum-specific human memory B cell compartment expands gradually with repeated malaria infections. PloS Pathog. 6, e1000912. doi: 10.1371/journal.ppat.1000912

White, N. J., Turner, G. D., Medana, I. M., Dondorp, A. M., and Day, N. P. (2010). The murine cerebral malaria phenomenon. Trends Parasitol. 26, 11-15. doi: 10.1016/j.pt.2009.10.007

WHO. World Malaria Report 2019. Available at: https://www.who.int/publications/i/ item/9789241565721.

Wijayalath, W., Danner, R., Kleschenko, Y., Majji, S., Villasante, E. F., Richie, T. L., et al. (2014). HLA class II (DR0401) molecules induce Foxp3+ regulatory T cell suppression of B cells in Plasmodium yoelii strain 17XNL malaria. Infect. Immun. 82, 286-297. doi: 10.1128/IAI.00272-13

Wu, J., Tian, L., Yu, X., Pattaradilokrat, S., Li, J., Wang, M., et al. (2014). Strainspecific innate immune signaling pathways determine malaria parasitemia dynamics and host mortality. Proc. Natl. Acad. Sci. U.S.A. 111, E511-E520. doi: 10.1073/pnas.1316467111

Wu, J., Xia, L., Yao, X., Yu, X., Tumas, K. C., Sun, W., et al. (2020). The E3 ubiquitin ligase $\mathrm{MARCH} 1$ regulates antimalaria immunity through interferon signaling and T cell activation. Proc. Natl. Acad. Sci. U.S.A. 117, 16567-16578. doi: 10.1073/pnas.2004332117

Wykes, M. N., and Good, M. F. (2008). What really happens to dendritic cells during malaria? Nat. Rev. Microbiol. 6, 864-870. doi: 10.1038/nrmicro1988

Wykes, M. N., Liu, X. Q., Beattie, L., Stanisic, D. I., Stacey, K. J., Smyth, M. J., et al. (2007). Plasmodium strain determines dendritic cell function essential for survival from malaria. PloS Pathog. 3, e96. doi: 10.1371/journal.ppat.0030096

Xia, L., Wu, J., Pattaradilokrat, S., Tumas, K., He, X., Peng, Y. C., et al. (2018). Detection of host pathways universally inhibited after Plasmodium yoelii infection for immune intervention. Sci. Rep. 8, 15280. doi: 10.1038/s41598018-33599-1

Yagi, H., Nomura, T., Nakamura, K., Yamazaki, S., Kitawaki, T., Hori, S., et al. (2004). Crucial role of FOXP3 in the development and function of human CD25+CD4+ regulatory T cells. Int. Immunol. 16, 1643-1656. doi: 10.1093/ intimm/dxh165

Yao, X., Wu, J., Lin, M., Sun, W., He, X., Gowda, C., et al. (2016). Increased CD40 Expression Enhances Early STING-Mediated Type I Interferon Response and Host Survival in a Rodent Malaria Model. PloS Pathog. 12, e1005930. doi: 10.1371/journal.ppat. 1005930

Young, M. R., and Colburn, N. H. (2006). Fra-1 a target for cancer prevention or intervention. Gene 379, 1-11. doi: 10.1016/j.gene.2006.05.001 
Yu, Y., and Hayward, G. S. (2010). The ubiquitin E3 ligase RAUL negatively regulates type i interferon through ubiquitination of the transcription factors IRF7 and IRF3. Immunity 33, 863-877. doi: 10.1016/j.immuni.2010.11.027

Yu, X., Harden, K., Gonzalez, L. C., Francesco, M., Chiang, E., Irving, B., et al. (2009). The surface protein TIGIT suppresses T cell activation by promoting the generation of mature immunoregulatory dendritic cells. Nat. Immunol. 10, 48-57. doi: 10.1038/ni.1674

Yu, X., Cai, B., Wang, M., Tan, P., Ding, X., Wu, J., et al. (2016). Cross-Regulation of Two Type I Interferon Signaling Pathways in Plasmacytoid Dendritic Cells Controls Anti-malaria Immunity and Host Mortality. Immunity 45, $1093-$ 1107. doi: 10.1016/j.immuni.2016.10.001

Yu, X., Du, Y., Cai, C., Cai, B., Zhu, M., Xing, C., et al. (2018). Inflammasome activation negatively regulates MyD88-IRF7 type I IFN signaling and antimalaria immunity. Nat. Commun. 9, 4964. doi: 10.1038/s41467-018-07384-7

Zander, R. A., Obeng-Adjei, N., Guthmiller, J. J., Kulu, D. I., Li, J., Ongoiba, A., et al. (2015). PD-1 Co-inhibitory and OX40 Co-stimulatory Crosstalk Regulates Helper T Cell Differentiation and Anti-Plasmodium Humoral Immunity. Cell Host. Microbe 17, 628-641. doi: 10.1016/j.chom.2015.03.007

Zander, R. A., Guthmiller, J. J., Graham, A. C., Pope, R. L., Burke, B. E., Carr, D. J., et al. (2016). Type I Interferons Induce T Regulatory 1 Responses and Restrict Humoral Immunity during Experimental Malaria. PloS Pathog. 12, e1005945. doi: 10.1371/journal.ppat.1005945

Zander, R. A., Vijay, R., Pack, A. D., Guthmiller, J. J., Graham, A. C., Lindner, S. E., et al. (2017). Th1-like Plasmodium-Specific Memory CD4(+) T Cells Support Humoral Immunity. Cell Rep. 21, 1839-1852. doi: 10.1016/j.celrep.2017.10.077
Zhang, Y., Jiang, N., Zhang, T., Chen, R., Feng, Y., Sang, X., et al. (2019a). Tim-3 signaling blockade with alpha-lactose induces compensatory TIGIT expression in Plasmodium berghei ANKA-infected mice. Parasit. Vectors 12, 534. doi: 10.1186/s13071-019-3788-x

Zhang, Y., Tada, T., Ozono, S., Yao, W., Tanaka, M., Yamaoka, S., et al. (2019b). Membrane-associated RING-CH (MARCH) 1 and 2 are MARCH family members that inhibit HIV-1 infection. J. Biol. Chem. 294, 3397-3405. doi: 10.1074/jbc.AC118.005907

Zhu, J., Krishnegowda, G., and Gowda, D. C. (2005). Induction of proinflammatory responses in macrophages by the glycosylphosphatidylinositols of Plasmodium falciparum: the requirement of extracellular signal-regulated kinase, p38, c-Jun $\mathrm{N}$-terminal kinase and NF-kappaB pathways for the expression of proinflammatory cytokines and nitric oxide. J. Biol. Chem. 280, 8617-8627. doi: 10.1074/jbc.M413539200

Conflict of Interest: The authors declare that the research was conducted in the absence of any commercial or financial relationships that could be construed as a potential conflict of interest.

Copyright $\odot 2020 \mathrm{Cai}, \mathrm{Hu}$ and $\mathrm{Yu}$. This is an open-access article distributed under the terms of the Creative Commons Attribution License (CC BY). The use, distribution or reproduction in other forums is permitted, provided the original author(s) and the copyright owner(s) are credited and that the original publication in this journal is cited, in accordance with accepted academic practice. No use, distribution or reproduction is permitted which does not comply with these terms. 